Aus der Klinik für Anästhesiologie

(Prof. Dr. med. M. Quintel)

im Zentrum Anaesthesiologie, Rettungs- und Intensivmedizin

der Medizinischen Fakultät der Universität Göttingen

\title{
Einfluss des eNOS T-786C-Polymorphismus auf die 5-Jahres-Mortalität und -Morbidität von Patienten nach herzchirurgischen Eingriffen
}

\author{
INAUGURAL-DISSERTATION \\ zur Erlangung des Doktorgrades \\ der Medizinischen Fakultät \\ der Georg-August-Universität zu Göttingen
}

vorgelegt von

Christian Bireta

aus Jawor / Polen

Göttingen 2013 
Dekan:

1. Berichterstatter:

2. Berichterstatter:

3. Berichterstatter:
Prof. Dr. rer. nat. H. K. Kroemer

Prof. Dr. med. J. Hinz

Prof. Dr. H. Bickeböller

Prof. Dr. med. J. Brockmöller

Tag der mündlichen Prüfung: $\quad$ 14.04.2015 



\section{Inhaltsverzeichnis}

Abkürzungsverzeichnis

1. Einleitung 1

1.1. Stickstoffmonoxid (NO) 1

1.1.1. Molekulare Eigenschaften 2

1.1.2. Synthese und Abbau 3

1.1.3. Wirkungen und Zielmoleküle 5

1.1.4. Rolle im Herz-Kreislauf-System 8

1.1.5. Einfluss herzchirurgischer Eingriffe auf die NO-Synthese 11

1.2. Genom und Genpolymorphismus 15

$\begin{array}{ll}\text { 1.2.1. eNOS T-786C-Polymorphismus } & 16\end{array}$

$\begin{array}{lll}\text { 1.3. Zielsetzung } & 21\end{array}$

2. Material und Methoden $\quad 22$

2.1. Patientenkollektiv und Studienkonzept 22

2.2. Datenerhebung 23

2.2.1. Vorangegangene Datenerhebung 24

2.2.2. Aktuelle Datenerhebung 25

2.3. Statistische Analyse 31

3. Ergebnisse $\quad 32$

3.1. Auswertung und Analyse des Patientenkollektivs 32

3.2. Genotypen und Allelverteilung 36

3.3. Prä- und intraoperative Daten 37

3.4. Morbidität im Langzeitverlauf 38

3.5. Mortalität im Langzeitverlauf 39

4. Diskussion $\quad 45$

5. Zusammenfassung $\quad 55$

6. Literaturverzeichnis $\quad 58$

$\begin{array}{ll}\text { 7. Abbildungsverzeichnis } & 71\end{array}$

8. Tabellenverzeichnis $\quad 72$ 


\section{Abkürzungsverzeichnis}

\begin{tabular}{|c|c|}
\hline ADP & Adenosindiphosphat \\
\hline ALS & Amyotrophe Lateralsklerose \\
\hline $\mathrm{BH}_{4}$ & Tetrahydrobiopterin \\
\hline $\mathrm{C}$ & Cytosin \\
\hline $\mathrm{CaM}$ & Calmodulin \\
\hline cGMP & zyklisches Guanosin-3'5'-Monophosphat \\
\hline cNOS & konstitutive NO-Synthase \\
\hline $\mathrm{CNV}$ & Copy Number Variation \\
\hline COPD & chronisch obstruktive Lungenerkrankung \\
\hline $\mathrm{COX}$ & Cyclooxygenase \\
\hline DNS, DNA & Desoxyribonukleinsäure \\
\hline EDRF & Endothelial Derived Relaxing Factor \\
\hline EDTA & Ethylendiamintetraessigsäure \\
\hline $\mathrm{EF}$ & Ejektionsfraktion \\
\hline EKZ & extrakorporale Zirkulation \\
\hline eNOS & endotheliale NO-Synthase \\
\hline EuroSCORE & European System for Cardiac Operative Risk Evaluation \\
\hline FAD & Flavinadenindinukleotid \\
\hline FMN & Flavinmononukleotid \\
\hline GTP & Guanosintriphosphat \\
\hline HLM & Herz-Lungen-Maschine \\
\hline HWG & Hardy-Weinberg-Gleichgewicht \\
\hline IFN- $\gamma$ & Interferon- $\gamma$ \\
\hline iNOS & induzierbare NO-Synthase \\
\hline $\mathrm{kB}$ & Kilobasen \\
\hline $\mathrm{kDa}$ & Kilodalton \\
\hline KHK & koronare Herzerkrankung \\
\hline LDL & Low Density Lipoproteine \\
\hline LPS & Lipopolysaccharide \\
\hline mRNA & Messenger-Ribonukleinsäure \\
\hline
\end{tabular}




\begin{tabular}{|c|c|}
\hline MRRG & Melderechtsrahmengesetz \\
\hline $\mathrm{N}_{2} \mathrm{O}_{3}$ & Distickstofftrioxid \\
\hline NADPH & Nikotinamid-Adenin-Dinukleotid-Phosphat \\
\hline nNOS & neuronale NO-Synthase \\
\hline NO & Stickstoffmonoxid \\
\hline $\mathrm{NO}_{2}^{-}$ & Nitrit \\
\hline $\mathrm{NO}_{3}^{-}$ & Nitrat \\
\hline NOS & NO-Synthasen \\
\hline $\mathrm{O}_{2}$ & Sauerstoff \\
\hline $\mathrm{O}_{2}^{-}$ & Superoxid-Anion \\
\hline $\mathrm{ONNO}^{-}$ & Peroxynitritanion \\
\hline PAPmean & pulmonaler arterieller Mitteldruck \\
\hline PCR & Polymerase-Kettenreaktion \\
\hline PEGASUS & Perioperative Genetics and Safety Outcome Study \\
\hline PKG & Proteinkinase $\mathrm{G}$ \\
\hline $\mathrm{pO}_{2}$ & Sauerstoffpartialdruck \\
\hline RNOS & Reactive Nitrogen Oxide Species \\
\hline RPA1 & Replication Protein A1 \\
\hline sGC & Soluble Guanylat Cyclase, lösliche Guanylatzyklase \\
\hline SIRS & Systemic Inflammatory Response Syndrome \\
\hline SNP & Single Nucleotide Polymorphism \\
\hline $\mathrm{T}$ & Thymin \\
\hline THG & Thorax-, Herz- und Gefäßchirurgie \\
\hline UMG & Universitätsmedizin Göttingen \\
\hline UV & ultraviolette Strahlung \\
\hline ZNS & Zentrales Nervensystem \\
\hline
\end{tabular}




\section{Einleitung}

\subsection{Stickstoffmonoxid (NO)}

Nach wie vor stellen Krankheiten des Herz-Kreislauf-Systems die häufigste Todesursache in den westlichen Industrienationen dar. Allein in Deutschland verstarben 2011342.233 Menschen an Krankheiten des Herz-Kreislauf-Systems. Gemessen an der Gesamtmortalität entspricht dies ca. 40\%. Somit erlag 2011 beinahe jeder zweite Verstorbene kardiovaskulären Erkrankungen (Statistisches Bundesamt 2012). Zusätzlich verursachen diese Erkrankungen einen immensen Kostenaufwand im Gesundheitssystem. In Deutschland waren es 2008 fast 37 Milliarden Euro (Statistisches Bundesamt 2010). Betrachtet man diesen Hintergrund, so erscheint es, dass der Prävention in diesem Bereich eine große Rolle zukommt.

Die meisten kardiovaskulären Erkrankungen gehen mit Veränderungen des Blutgefäßsystems wie z.B. der Atherosklerose und Endotheldysfunktionen einher. Somit kommt dem Schutz der Blutgefäße gegenüber pathologischen Einflüssen eine besondere Rolle zu. Einen solchen Schutzmechanismus vermittelt die endotheliale Produktion von NO, bzw. dessen Bioverfügbarkeit, die durch Vasodilatation und Thrombosehemmung vasoprotektiv wirkt. Die meisten Herz-Kreislauf-Erkrankungen gehen mit einer verminderten Bioverfügbarkeit des endothelialen NO einher und führen damit zu einer Endotheldysfunktion bzw. zu Störungen der Endothelintegrität (Gewaltig und Kojda 2002, Traub und Berk 1998).

Im Jahre 1980 entdeckten Furchgott und Zawadzki eine Substanz, die aus Endothelzellen freigesetzt wird und zu einer Relaxation der glatten Gefäßmuskelzellen führt. Diese Substanz wurde zunächst aufgrund ihres Entstehungsortes und ihrer Wirkung als endothelial derived relaxing factor (EDRF) bezeichnet (Furchgott und Zawadzki 1980). 1987 identifizierten Ignarro und Palmer mit ihren Arbeitsgruppen unabhängig voneinander diese Substanz als NO (Stickstoffmonoxid) (Ignarro et al. 1987, Moncada et al. 1988, Palmer et al. 1987). Für die Grundlagenforschung in diesem 
Bereich erhielten Furchgott und Ignarro zusammen mit Ferid Murad 1998 den Nobelpreis für Medizin und Physiologie (Bian et al. 2008, Snyder 2009).

\subsubsection{Molekulare Eigenschaften}

Bei NO handelt es sich um ein farbloses Molekül, welches unter atmosphärischen Bedingungen als Gas vorliegt und aufgrund seines hohen Verteilungskoeffizienten schlecht wasserlöslich ist. Da es in wässriger Lösung bis zu einer Konzentration von 2 $\mathrm{mM}$ löslich ist und die physiologische und pathophysiologische Konzentration den $\mu \mathrm{M}$ Bereich nicht überschreitet, liegt es im menschlichen Organismus in gelöster Form vor (Kröncke et al. 2000). Es besitzt ein ungepaartes Elektron, welches ihm die Natur eines freien Radikals verleiht und damit seine hohe Reaktivität erklärt. Gemessen an der Reaktionsfreudigkeit anderer Radikale ist sie jedoch gering (Beckman und Koppenol 1996, Kelm 1999). NO hat eine kurze und von vielen Faktoren abhängige Halbwertszeit. Somit ist die Halbwertszeit in biologischen Systemen eine nicht konstante Größe. Zu den Faktoren, die die Halbwertszeit beeinflussen, zählen die eigentliche NO-Konzentration (Hauptfaktor), der NO-Metabolismus, das Diffusionsvermögen, der $\mathrm{pH}-$ Wert der Lösung, der Sauerstoffpartialdruck $\left(\mathrm{pO}_{2}\right)$ und das Vorhandensein bzw. die Konzentration von biologischen Reaktionspartnern (wie z.B. lösliche Guanylatzyklase (sGC), Übergangsmetalle, Hämoglobin und andere Radikale) (Beckman und Koppenol 1996, Kelm 1999). Da NO neben seiner kleinen Molekülgröße eine Ladungsneutralität aufweist, ist es sowohl in Wasser als auch in Lipiden löslich. Dadurch kann es frei durch zytosolische und membranöse Kompartimente diffundieren. Zusätzlich besitzt es eine hohe Diffusionskonstante, die 1,4mal höher ist als die von Sauerstoff $\left(\mathrm{O}_{2}\right)$ (Beckman und Koppenol 1996, Kelm 1999). Ausgehend von einer punktförmigen Bildungsquelle wie z.B. einer Endothelzelle, kann es, wenn es für wenige Sekunden freigesetzt wird, etwa $200 \mu \mathrm{m}$ weit diffundieren. Aufgrund dieser molekularen Eigenschaften werden für die Wirkungsvermittlung von NO keine extrazellulären Rezeptoren benötigt (Butler et al. 1998, Wood und Garthwaite 1994). 


\subsubsection{Synthese und Abbau}

NO wird im menschlichen Körper durch die in verschiedenen Zellen vorkommenden NO-Synthasen (NOS) enzymatisch produziert. NOS katalysieren in Anwesenheit von molekularem Sauerstoff und NADPH (reduzierte Form von Nikotinamid-Adenin-Dinukleotid-Phosphat) die 5-Elektronen-Oxidation der semiessentiellen Aminosäure L-Arginin zu äquimolaren Mengen an NO und L-Citrullin. Dabei wird sowohl in NO als auch in L-Citrullin molekularer Sauerstoff eingebaut (Förstermann und Sessa 2012, Kwon et al. 1990). Das Stickstoffatom im NO-Molekül stammt aus der terminalen Guanidinogruppe von L-Arginin. NADPH und $\mathrm{O}_{2}$ stellen bei diesen katalytischen Vorgängen wichtige Kosubstrate dar. Weitere Kofaktoren, die für die NO-Synthese benötigt werden, sind Flavinadenindinukleotid (FAD), Flavinmononukleotid (FMN) und Tetrahydrobiopterin $\left(\mathrm{BH}_{4}\right)$ (Förstermann und Sessa 2012, Förstermann et al. 1994).

Die Enzymfamilie der NO-Synthasen umfasst drei Isoformen (eNOS, nNOS, iNOS), die von unterschiedlichen Genen kodiert werden und sich zunächst nach ihrem Aktivierungsmuster in konstitutive NOS (cNOS) und induzierbare NOS (iNOS) unterteilen lassen. Zu den konstitutiven NOS werden die endotheliale NOS (eNOS) und die neuronale NOS (nNOS) gezählt. Ihre Genloci wurden auf Chromosom 12 (nNOS), 17 (iNOS) und 7 (eNOS) lokalisiert. Alle weisen eine gemeinsame Grundstruktur mit einer Reduktase-Domäne am C-Terminus und einer Oxygenase-Domäne am N-Terminus auf. Das aktive NOS-Protein ist ein Homodimer mit Kopf an Kopf angeordneten Untereinheiten und interagierenden Oxygenase-Domänen. Calmodulin $(\mathrm{CaM})$ vermittelt dabei substratunabhängig den Elektronenfluss zwischen den beiden Domänen und dient somit als ein Scharnier (Förstermann und Sessa 2012, Förstermann et al. 1994).

Die Nomenklatur der NO-Synthasen kommt durch die ursprüngliche Benennung der Isoformen nach den Geweben, aus denen sie erstmalig gewonnen wurden, zustande. Diese sind in der Zwischenzeit jedoch in vielen anderen Zelltypen gefunden und charakterisiert worden. Die erste Isoform, die isoliert und kloniert werden konnte, 
entstammt dem Kleinhirn von Ratten und Schweinen. Sie wird dementsprechend als neuronale NOS (nNOS) oder NOS I bezeichnet. Sie wird konstitutiv exprimiert und ihre Aktivierung ist Kalzium-/Calmodulin-abhängig (Förstermann und Sessa 2012). Ihr Molekulargewicht beträgt $161 \mathrm{kDa}$ (Kilodalton) und ihr Genlocus befindet sich auf Chromosom 12 (12q24.2 $\rightarrow$ 24.31) (Förstermann et al. 1994).

Die zweite NO-Synthase, die identifiziert werden konnte, wurde in Lipopolysaccharid (LPS) und Interferon- $\gamma($ IFN- $\gamma)$ stimulierten murinen Makrophagen entdeckt. Im Gegensatz $\mathrm{zu}$ der nNOS und eNOS wird sie normalerweise nicht konstitutiv exprimiert, sondern kann durch proinflammatorische Stimuli wie bakterielle Lipopolysaccharide, Zytokine und UV-Strahlung, in fast allen bekannten Zelltypen induziert werden. Deswegen wird sie auch als induzierbare NO-Synthase (iNOS) oder NOS II bezeichnet. Die Induktion kann eine schnelle Freisetzung großer NO-Mengen bewirken, die über Stunden bis Tage aufrechterhalten werden kann. Diese hohen NO-Konzentrationen spielen eine wichtige Rolle in der Immunabwehr von Bakterien, Parasiten, Pilzen und Neoplasien, können aber auch die eigenen Körperzellen schädigen (Förstermann und Sessa 2012). Die Aktivität der NOS II ist im Gegensatz zu den beiden anderen Isoformen kalziumunabhängig. Dies liegt daran, dass sich innerhalb ihrer CaM-Domäne bereits ein stark gebundener Calmodulin-Komplex befindet, der zu einer dauerhaften Aktivierung und damit zu einer Unabhängigkeit gegenüber transienten intrazellulären Kalzium-Spiegeln führt. Die NOS II weist ein Molekulargewicht von $131 \mathrm{kDa}$ auf und ihr Genlocus befindet sich auf Chromosom $17(17 \mathrm{p} .11 \rightarrow 17 \mathrm{q} 11)$ (Förstermann et al. 1994, Kröncke et al. 2000).

Obwohl die Entdeckung des NO als Signalmolekül zuerst aus den Endothelzellen gelang, wurde die hierfür verantwortliche NO-Synthase als letzte Isoform identifiziert und kloniert. Sie wird als endotheliale NOS (eNOS) oder NOS III bezeichnet und weist ein Molekulargewicht von $133 \mathrm{kDa}$ auf. Ihr Genlocus befindet sich auf Chromosom 7 (7q35 $\rightarrow$ 7q36) (Förstermann et al. 1994). Neben den Endothelzellen konnte sie auch in Kardiomyozyten, Skelettmuskelzellen, Epithelzellen und Fibroblasten nachgewiesen werden. Die eNOS wird wie die nNOS konstitutiv exprimiert und ist ebenfalls Kalzium-/Calmodulin-abhängig. Jedoch gibt es für sie auch einen kalziumunabhängigen Weg, der in Kapitel 1.1.4. näher beschrieben wird (Förstermann und Sessa 2012). Bei der kalziumabhängigen Aktivierung kommt es zu einem Kalziumeinstrom in die Zelle 
und $\mathrm{zu}$ einer Calmodulinbindung. Die hieraus resultierenden Kalzium-/CalmodulinKomplexe binden an die CaM-Domäne der konstitutiven NO-Synthasen, wodurch eine aktivierende Konformationsänderung dieser bewirkt und $\mathrm{NO}$ in physiologischen Konzentrationen produziert wird. Die für die eNOS-Aktivität nötige Kalziumfreisetzung kann durch Agonisten wie Acetylcholin, Bradykinin, Thrombin, Histamin etc. geschehen (Govers und Rabelink 2001).

Da es für NO keinen katalytischen Abbauweg im menschlichen Körper gibt, spricht man bei der Elimination eher von einem Verbrauch als von einem Abbau. Die Elimination erfolgt auf unterschiedliche Art und Weise und hängt zunächst von der gebildeten NO-Menge, von dem Vorhandensein an Reaktionspartnern und von der Lokalisation der NO-Bildung ab (Joshi et al. 2002, Kelm 1999). Im Plasma oder im Gewebe, also in Abwesenheit von Hämoglobin, wird der größte Teil mit molekularem Sauerstoff zu Nitrit $\left(\mathrm{NO}_{2}{ }^{-}\right)$oxidiert. Diffundiert das NO durch das benachbarte Gewebe in das Gefäßsystem und somit in die Erythrozyten, so wird es in Anwesenheit von oxygeniertem Hämoglobin durch Bindung an die Hämgruppe des Oxy-Hämoglobins ohne enzymatische Katalyse zu Nitrat $\left(\mathrm{NO}_{3}{ }^{-}\right)$und Methämoglobin umgesetzt. Das bei den Verbrauchsprozessen gebildete Nitrat wird zum größten Teil mit dem Urin ausgeschieden (Joshi et al. 2002, Kelm 1999).

\subsubsection{Wirkungen und Zielmoleküle}

Neben seiner vasodilatatorischen Wirkung und damit Regulation des Vasotonus fungiert NO im Menschen als ein autokriner und parakriner Regulator einer Vielzahl physiologischer Funktionen. Das Molekül stellt jedoch aufgrund seines Radikalcharakters auch ein potentes zelluläres Toxin dar, das unter normalen Umständen den menschlichen Körper vor eindringenden Pathogenen oder Tumorzellen schützt, aber auch mit diesem Mechanismus körpereigene Zellen zerstören kann. Letzteres spielt eine wichtige Rolle bei der Immunabwehr sowie der Pathogenese verschiedener Autoimmunerkrankungen (Förstermann und Sessa 2012, Schmidt und Walter 1994). Diese Diskrepanz zwischen reinem Transmitter und potentem Toxin lässt sich durch die zwei möglichen Reaktionen, die von der NO-Konzentration, dem 
Bildungsort, der Produktionsdauer und den vorhandenen Reaktionspartnern abhängig ist, erklären. Aufgrund dessen unterscheidet man bei den biologischen Effekten von NO auf der einen Seite die direkten - NO-vermittelten Effekte, von den auf der anderen Seite indirekten - Radikal-vermittelten Effekten. Indirekte Effekte können weiter in Nitrosierungs-, Oxidations- und Nitrierungsreaktionen unterteilt werden (Kröncke et al. 2000, Wink und Mitchell 1998).

Direkte Effekte sind schnelle Reaktionen, die bei niedrigen NO-Konzentrationen $(<1 \mu \mathrm{M})$ ablaufen. Anders als Zytokine oder Hormone bindet dabei das NO-Molekül nicht an einen spezifischen Rezeptor, sondern kann direkt mit Eisengruppen von Zielmolekülen und anderen freien Radikalen reagieren und dadurch entweder die Enzymaktivität modulieren oder zytoprotektiv bzw. antioxidativ wirken (Kröncke et al. 2000, Wink und Mitchell 1998). Das bekannteste Beispiel für eine Reaktion mit Eisengruppen in häm-haltigen Proteinen und eine Enzymmodulation ist die Aktivierung der löslichen Guanylatzyklase, dem wohl wichtigsten Reaktionspartner des NO. Das durch die NOS synthetisierte NO bindet dabei an die Eisen(II)Häm-Gruppe des Enzyms, welches nach einleitender Konformationsänderung verstärkt zyklisches Guanosin-3'5'-Monophosphat (cGMP) aus Guanosintriphosphat (GTP) bildet. Das entstandene cGMP hat die Funktion eines second messenger und fungiert als Vermittler zahlreicher regulatorischer Funktionen (Förstermann und Sessa 2012, Waldman und Murad 1988). Beim Endothel führt das entstandene cGMP zu der Aktivierung der Proteinkinase G (PKG), welches mit einer Abnahme der intrazellulären Kalziumkonzentration sowie einer Relaxation der glatten Gefäßmuskulatur, Verminderung des Blutdrucks und einer verstärkten lokalen Durchblutung verbunden ist. Zusätzlich kommt es hierbei zu einer verringerten Thrombozytenadhäsion an der Gefäßwand, geringerer Vernetzung der Plättchen untereinander und zu der Hemmung des weiteren Rekrutierens dieser. Durch diesen Mechanismus wirkt NO protektiv auf das Endothel und verhindert Schlaganfälle, Thrombosen und Myokardinfarkte (Moncada et al. 1988, Wink und Mitchell 1998).

Weitere direkte Effekte des NO dienen der Neurotransmission, der Synaptogenese und der synaptischen Plastizität. Außerdem spielt NO eine wichtige Rolle bei 
sensorischen Prozessen wie der Schmerzwahrnehmung und bei der Entstehung des Erinnerungsvermögens (Förstermann und Sessa 2012). An der Niere führt es über Erhöhung der glomerulären Perfusion zu einer erhöhten Ausscheidung harnpflichtiger Substanzen und erhöht die Reninsekretion. Aufgrund seiner ebenfalls hohen Affinität zu anderen freien Radikalen weist es zusätzlich antioxidative Eigenschaften auf, die zytoprotektiv wirken (Schmidt und Walter 1994, Wink und Mitchell 1998).

Anders als die direkten Effekte werden die indirekten bzw. Radikal-vermittelten Effekte von NO über die reactive nitrogen oxide species (RNOS) vermittelt. Die RNOS können bei hohen lokalen NO-Konzentrationen $(>1 \mu \mathrm{M})$, die über einen längeren Zeitraum vorliegen, aus der Reaktion von NO mit molekularem Sauerstoff oder mit dem Superoxid-Anion $\left(\mathrm{O}_{2}^{-}\right)$entstehen. Sie können die Zellen in oxidativen sowie nitrosativen Stress versetzen und somit zu einer Zellschädigung führen. Die beiden wichtigsten Vertreter im menschlichen Körper sind das Peroxynitrit (ONNO-) und das Distickstofftrioxid $\left(\mathrm{N}_{2} \mathrm{O}_{3}\right)$ (Wink und Mitchell 1998). Hohe lokale NO-Konzentrationen werden vor allem während entzündlicher Prozesse durch die iNOS synthetisiert. Hierbei ist jedoch die RNOS-Bildung teilweise gewünscht, da sie zytotoxisch auf die Pathogene wirken kann. Da es im menschlichen Körper mehrere Kontrollinstanzen für die NObzw. RNOS-Konzentration gibt, wirkt nicht jede hohe NO-Konzentration gleich zytotoxisch auf die menschlichen Zellen (Kröncke et al. 2000, Miller und Sandoval 1999).

Peroxynitrit, eines der stärksten zellulären Oxidationsmittel in biologischen Systemen, entsteht aus der Reaktion des Superoxid-Anions $\left(\mathrm{O}_{2}{ }^{-}\right)$mit NO und ist in der Lage, die Funktionsweise einer Vielzahl von Molekülen zu modifizieren (Förstermann und Sessa 2012). Die durch die Oxidation und Nitration ausgelösten Proteinfragmentierungen, Hemmungen wichtiger Schlüsselenzyme sowie Senkung des Redoxpotentials einer Zelle, können zu pathologischen Zuständen führen (Squadrito und Pryor 1998, Wink und Mitchell 1998). So konnten erhöhte Peroxynitritkonzentrationen bei einer Vielzahl an Erkrankungen wie der Alzheimer Erkrankung, der rheumatoiden Arthritis, der Arteriosklerose, der amyotrophen Lateralsklerose (ALS) 
und vielen mehr beobachtet werden (Förstermann und Sessa 2012, Squadrito und Pryor 1998).

Der zweite wichtige Vertreter der RNOS ist das Distickstofftrioxid. Es entsteht aus der Reaktion von NO mit molekularem Sauerstoff. Dieser Prozess wird als Autooxidation des NO bezeichnet. Das Distickstofftrioxid ist hauptsächlich für den nitrosativen Stress, der von den RNOS ausgeht, verantwortlich. Zielmoleküle sind vor allem Thiole und Amine (Wink und Mitchell 1998). Unter physiologischen Umständen handelt es sich hierbei um reversible Prozesse, die eine wichtige Rolle bei der Signaltransduktion spielen und die Funktion vieler intrazellulärer Proteine regulieren. Kommt es während pathophysiologischer Prozesse (z.B. einer Infektion) zu einer erhöhten Bildung von Distickstofftrioxid, erhöht sich folglich die Nitrosierungsrate der Zielmoleküle. Somit kommt es zum nitrosativen Stress der Zellen bzw. des Gewebes, mit der Folge der Zellschädigung und Zellzerstörung. Erhöhte Nitrosamin- und Nitrothiolkonzentrationen können zusätzlich mutagen und karzinogen wirken (Kröncke et al. 2000, Miller und Sandoval 1999).

\subsubsection{Rolle im Herz-Kreislauf-System}

NO nimmt aufgrund seiner vielfältigen Wirkungen im Herz-Kreislauf-System eine Schlüsselposition ein. Neben dem Gefäßsystem wirkt es vor allem direkt am Herzen und an der Lunge. Die wichtigste Funktion ist jedoch die Vasodilatation zur physiologischen Autoregulation des gesamten Gefäßsystems. NO wird dabei in geringen Mengen kontinuierlich vom Endothel produziert und freigesetzt. Eine Steigerung der Produktion kann durch die bereits erwähnten Agonisten wie Acetylcholin, Bradykinin etc. erfolgen (Böger et al. 1996, Gewaltig und Kojda 2002). Den wichtigsten Aktivierungsweg im menschlichen Körper für die eNOS stellt jedoch die endogene kalzium- und agonistenunabhängige Aktivierung durch shear stress (Scherkräfte) dar. Durch die mechanische Belastung des Endothels durch Scherkräfte und pulsatile Blutdruckschwankungen kommt es zu der Aktivierung von intrazellulären Proteinkinasen, welche eine Phosphorylierung der eNOS und eine vermehrte Kalziumausschüttung aus intrazellulären Speichern bewirken. Die Phosphorylierung 
führt $\mathrm{zu}$ einer eNOS Aktivierung und damit konsekutiv $\mathrm{zu}$ der vermehrten NO-Synthese. Die anschließende Vasodilatation dient dem Endothel dazu sich selbst vor einer mechanischen Überbelastung zu schützen (Berk et al. 1995, Corson et al. 1996). Der schnellen und kurzfristigen Entlastung folgt bei weiter anhaltender mechanischer Belastung eine langfristige Bereitstellung der eNOS durch ihre Neusynthese. Das eNOS-Gen besitzt hierfür insgesamt zwei sogenannte shear stress response elements innerhalb seiner Promotorregion, die spezifisch $\mathrm{zu}$ der erhöhten Transkription des eNOS-Gens bei erhöhter mechanischer Belastung führen. Dieser gesamte Mechanismus der eNOS-Aktivierung spielt eine entscheidende Rolle bei der Autoregulation des Gefäßtonus und somit der Gewebeperfusion (Berk et al. 1995, Cheng et al. 2005, Uematsu et al. 1995).

An bestimmten Lokalisationen im Gefäßsystem, insbesondere an Stellen an denen geringe Scherkräfte vorherrschen, kann es aber zu gegenteiligen Reaktionen kommen. Diese Schwachstellen liegen vor allem an Gefäßaufzweigungen, da es hier zu der vermehrten Bildung von Turbulenzen durch den Blutstrom kommt und damit zu geringeren Scherkräften (Chatzizisis et al. 2007, Traub und Berk 1998). Neben der eingeschränkten Aktivierung und verminderten Expression führen aber auch ein Substrat- oder Kofaktorenmangel sowie ein beschleunigter Abbau von NO zu seiner geringeren Bioverfügbarkeit. Es konnte ebenfalls gezeigt werden, dass kardiovaskuläre Risikofaktoren wie die arterielle Hypertonie, die Hypercholesterinämie, der Nikotinabusus und der Diabetes mellitus mit einer verringerten basalen NO-Freisetzung einhergehen (Förstermann und Sessa 2012, Quyyumi et al. 1995). Durch diese Einflüsse und Mechanismen kommt es zu einer geringeren Bioverfügbarkeit von NO. Daraus kann sich eine Endotheldysfunktion mit mangelhafter Autoregulation entwickeln, die weitere pathologische Schritte nach sich zieht. Dabei kommt es zunächst zu einer Steigerung der Endothelpermeabilität für Low-Density Lipoproteine (LDL), die nach Aufnahme in Makrophagen zu der Bildung von Schaumzellen führen. Diese tragen wesentlich zu der Ausbildung atherosklerotischer Plaques bei. Ihre Entstehung wird als initialer Schritt in der Pathogenese der Arteriosklerose betrachtet. Zusätzlich kommt es $\mathrm{zu}$ einer verminderten Produktion synergistischer vasoaktiver und antithrombotischer Stoffe wie z.B. der Prostacycline, da NO normalerweise als Aktivator der 
Cyclooxygenase (COX) dient. Dies verstärkt ebenfalls die Endotheldysfunktion. Die Schaumzellbildung führt unter anderem zu einer weiteren Migration von Makrophagen und $\mathrm{zu}$ der Ausschüttung von chemotaktischen Entzündungsmediatoren und Wachstumsfaktoren. Diese bewirken eine Proliferation von glatten Muskelzellen in die Intima und führen somit zu einer Intimaverdickung, die im Prinzip eine Vorläuferstufe der atherosklerotischen Plaques bildet. Durch die daraus resultierende Lumeneinengung kommt es $\mathrm{zu}$ der Bildung von Turbulenzen im Blutstrom und $\mathrm{zu}$ einer weiteren Abnahme der Scherkräfte, die wiederum zu einer zusätzlichen Abnahme der NO-Bioverfügbarkeit führt. Durch diesen Circulus vitiosus und durch die weiter anhaltenden inflammatorischen Reize kommt es schlussendlich zu der Ausbildung von atherosklerotischen Plaques. Atherosklerotische Veränderungen können zusätzlich zu einer Hyperreaktivität von Thrombozyten führen, wodurch nachfolgend Thrombosen und Embolien verursacht werden können (Böger et al. 1996, Chatzizisis et al. 2007, Gewaltig und Kojda 2002).

Da NO unter physiologischen Bedingungen nicht nur vasodilatierende Effekte aufweist, sondern andere vasoaktive Stoffe aktiviert, die Oxidation von LDL im Endothel und in den Makrophagen verhindert und zusätzlich die Leukozyten- und Thrombozytenadhäsion an der Gefäßwand, ihre weitere Rekrutierung und ihre Vernetzung untereinander hemmt, nimmt es einen direkten Einfluss auf die initialen Schritte der Arteriosklerose und verhindert diese. Außerdem hemmt NO die Inflammation, die Chemotaxis sowie die Proliferation der glatten Muskelzellen und wirkt damit der weiteren Plaquebildung entgegen. Aufgrund dieser antiatherogenen Mechanismen nimmt es im Rahmen der vaskulären Homöostase sowie der Entstehung der Arteriosklerose eine zentrale Stellung ein (Bian et al. 2008, Förstermann und Sessa 2012).

Das Endothel wirkt neben diesen Mechanismen auch als Hypoxie-Sensor des Kreislaufs, ein Effekt der ebenfalls durch die Wirkungen von NO vermittelt wird. NO kann an die katalytischen Zentren mitochondrialer Proteine wie der Cytochrom-C-Oxidase binden und durch eine Enzymhemmung die mitochondriale Elektronentransportkette unterbrechen. Dadurch wird der $\mathrm{O}_{2}$-Verbrauch der Zelle 
gesenkt und zusätzlich die Adenosintriphosphat-Produktion verringert, wodurch mehr Adenosin freigesetzt wird. Unter physiologischen Zuständen konkurriert hierbei NO mit $\mathrm{O}_{2}$ um dessen Bindungsstelle an der Cytochrom-C-Oxidase und die aktivierenden und inaktivierenden Wirkungen halten sich in Balance. Sinkt der $\mathrm{O}_{2}$-Druck ab, so überwiegt nun das kompetitiv hemmende NO und es kommt zu einer vermehrten Hemmung der Atmungskette mit der anschließenden Senkung des $\mathrm{O}_{2}$-Verbrauchs der Zelle und erhöhten Adenosinfreisetzung. Das freigesetzte Adenosin steigert wiederum die NO-Aktivität und es kommt $\mathrm{zu}$ einer Vasodilatation und damit $\mathrm{zu}$ einer besseren Perfusion des Gewebes mit der Steigerung des $\mathrm{O}_{2}$-Angebotes (Brown 1999, Edmunds et al. 2003). Ein zusätzlicher und ebenfalls wichtiger Mechanismus zu einer lokalen Verbesserung der Gewebeperfusion als Reaktion auf Hypoxien ist die Freisetzung von $\mathrm{NO}$ aus Erythrozyten. Die NO-Bildung ist hierbei an die $\mathrm{O}_{2}$-Sättigung des Hämoglobins der Erythrozyten gekoppelt. Sinkt diese bei drohender Gewebehypoxie, steigt die NO-Synthese (Crawford et al. 2006). An den Kardiomyozyten kommt neben diesen Mechanismen noch eine weitere Senkung des $\mathrm{O}_{2}$-Verbrauchs durch die Senkung der Herzfrequenz und die myokardiale Relaxation zustande (Seddon et al. 2007, Stumpe et al. 2001).

\subsubsection{Einfluss herzchirurgischer Eingriffe auf die NO-Synthese}

Für die meisten herzchirurgischen Eingriffe ist es notwendig, das Herz kardioplegisch stillzulegen und den Blutkreislauf und die Blutoxygenierung über eine extrakorporale Zirkulation (EKZ) aufrechtzuerhalten. Dies geschieht durch Anschluss des Patienten an eine Herz-Lungen-Maschine (HLM). Erst hiernach kann durch die Injektion einer kaliumreichen Lösung in die Koronararterien, der Kardioplegie, der kardioplegische Herzstillstand ausgelöst werden. Allein diese Schritte stellen schon einen erheblichen Eingriff in die physiologische Homöostase des menschlichen Organismus dar. Aber es kommt nicht nur zu einem Ungleichgewicht der Homöostase, vielmehr reagieren die verschiedenen Organe wie das Herz, die Lunge, die Niere, das Gehirn, die Skelettmuskulatur und das Immunsystem unterschiedlich auf die extrakorporale Zirkulation (Ruel et al. 2004). Außerdem kommt es zusätzlich zu einer veränderten Expression von hunderten von Genen des vaskulären Systems und 
assoziierter Organe. Die daraus resultierenden Veränderungen des Gefäßsystems und der Organe sind immens und unterliegen unterschiedlichen pathologischen Mechanismen (Ruel et al. 2003, Ruel et al. 2004).

Zuerst kommt es durch den Fremdflächenkontakt des Blutes mit der HLM zu einer Aktivierung humoraler (Komplementsystem, Gerinnungskaskade usw.) und zellulärer (Thrombozyten, Leukozyten usw.) Bestandteile. Die dadurch freigesetzten und im Blut zirkulierenden aggressiven Mediatoren und proinflammatorischen Zytokine können zu einer Endotheldysfunktion mit zirkulierenden Endothelzellen, dem teilweisen Barriereverlust der Gefäßwände und zu einer Vasokonstriktion führen. Durch den Barriereverlust der Gefäßwände kommt es zu einer erhöhten vaskulären Permeabilität, die mit peripheren Ödemen und Endorganödemen einhergehen kann (Butler et al. 1993, Ruel et al. 2004). Weitere Stimuli der Aktivierung der humoralen und zellulären Bestandteile sind die anfängliche Hypoxie, der Kontakt mit Thrombin und Endotoxinen, operationsbedingte Traumen (durch physikalische Manipulation oder Instrumente) und die hämodynamisch verursachte Scherspannung (Butler et al. 1993). Die Vasokonstriktion kann noch zusätzlich durch die stattfindende Hämolyse unter der HLM verstärkt werden, da Hämoglobin, wie eingangs erwähnt, den natürlichen Abbauweg für NO darstellt (De Souza und Spyt 1993). Die Gesamtheit dieser Prozesse führt zunächst zu einer Verminderung der vaskulären NO-Verfügbarkeit unter der HLM (Ruel et al. 2004, Ruvolo et al. 1994).

Als Antwort auf die Vasokonstriktion bzw. den daraus resultierenden shear stress und die ausgelöste Inflammation reagiert der Organismus physiologisch mit einer vermehrten Bildung von NO. Zu einem wird durch die verursachte Scherspannung (Vasokonstriktion, HLM-Material, Kardiotomiesauger) die endotheliale NO-Produktion angekurbelt, zum anderen triggern hierdurch aktivierte Thrombozyten durch die Produktion von Serotonin und Adenosindiphophat (ADP) die endotheliale NO-Synthese (Borgdorff et al. 2002, Fischer et al. 2007). Da Erythrozyten ebenso wie das Endothel über eine eNOS verfügen, sezernieren sie ebenfalls während einer extrakorporalen Zirkulation NO ins Gefäßlumen (Fischer et al. 2007). Desweiteren steigern Substanzen wie Bradykinin und Histamin, die als physiologische proinflammatorische Vasodilatatoren dienen, die NO-Synthese über den Agonisten- bzw. messenger- 
vermittelten Weg (Ruvolo et al. 1994). Zusätzlich führen Botenstoffe wie Interleukin 1, Interleukin 6 oder Tumornekrosefaktor- $\alpha$ ebenfalls $\mathrm{zu}$ der Stimulation der NO-Produktion, jedoch mit einer zeitlichen Verzögerung und entfalten ihre volle Wirkung erst während der initialen postoperativen Phase (Butler et al. 1993, Menasché et al. 1994). All diese Effekte führen $\mathrm{zu}$ einer erhöhten NO-Produktion mit anschließender Vasodilatation, die eine systemische Hypotension auslösen und eine durch die extrakorporale Zirkulation bedingte Hypotension verstärken kann (Menasché et al. 1994, Ruvolo et al. 1994, Sellke 1999). Wird die systemische Inflammation durch operationsbedingte Ereignisse (tiefe Hypothermie bei z.B. Aortenbogenersatz) oder Komplikationen (Blutungen, thrombembolische Ereignisse) aufrechterhalten, so kann es zu einem Systemic Inflammatory Response Syndrom (SIRS) kommen, welches mit Hyperthermie, Hypotension, Tachykardie, Tachypnoe und weiteren Symptomen einhergehen kann (Asimakopoulos 1999, Levin et al. 2004). Da NO hier für die Vasoplegie mit daraus resultierender Hypotension verantwortlich ist, kommen in der Therapie dieses vasoplegischen Schock-Syndroms Medikamente zum Einsatz, die die NO-Synthese bzw. die Inflammation bremsen oder die Zielmoleküle von NO beeinflussen (Levin et al. 2004, Ruel et al. 2004).

Neben den systemischen Reaktionen auf die extrakorporale Zirkulation reagieren die einzelnen Organe noch zusätzlich und sehr unterschiedlich auf diesen Fremdflächenkontakt. So verringert sich nach Erreichen des Herzstillstandes die eNOS-Aktivität unter der laufenden HLM innerhalb des Myokards, der Lungen, des Gehirns und des Mesenteriums, während es an der Niere zu einer Überexpression kommt. Verantwortlich hierfür sind veränderte Membranpotentiale, Kalziumkonzentrationen, Mangel an Substraten und Kofaktoren sowie Verletzungen von Membranen (Ruel et al. 2004, Sellke 1999).

Im Anschluss an den Herz-Kreislauf-Stillstand kommt es $\mathrm{zu}$ der Reperfusionsphase, die zu einer Erholung des Myokards und zu der Normalisierung des myokardialen Stoffwechsels führt. Sie wird idealerweise bei entlastetem, schlagendem Herzen und totaler extrakorporaler Zirkulation durchgeführt und dient dem Aufbau energieliefernder Substrate für das Herz. Während dieser Reperfusionsphase kann es 
vor allem am Myokard und der Lunge, aber auch an der Niere und anderen Organen zu erheblichen Reperfusionsschäden (reperfusion injury) kommen. Deshalb gilt diese Phase während herzchirurgischer Operationen als einer der kritischsten Momente, da es hierbei $\mathrm{zu}$ morphologischen, metabolischen und auch funktionellen Organschäden kommen kann (Tossios et al. 2003). Verantwortlich dafür ist der oxidative Stress, resultierend aus der Zunahme freier Radikale während und infolge der Ischämie und gleichzeitiger Abnahme der Antioxidantien durch Verbrauch und verminderte Produktion. Damit verschiebt sich das normalerweise vorherrschende Gleichgewicht zwischen oxidativen und antioxidativen Faktoren zu Gunsten der oxidativen mit der Entstehung vom oxidativen Stress (Ferrari et al. 1991, Tossios et al. 2003). Da NO wie bereits erwähnt antioxidative Eigenschaften aufweist, wird der Mangel an Antioxidantien auch durch die gedrosselte NO-Produktion während der HLM und durch dessen Kontakt mit Komplement-Fragmenten, neutrophilen Granulozyten und Makrophagen mit bedingt (Ruel et al. 2004, Sellke 1999). Um den Reperfusionsschaden so gering wie möglich zu halten bzw. ihn zu verhindern, kommt es während der Ischämiephase zu einer repetitiven Gabe von Kardioplegie. Das Ziel hierbei ist, die Sauerstoffradikale und die sauren Valenzen, die zu dem oxidativen Stress führen, zu eliminieren und den oxidativen Stress zu verhindern (Mezzetti et al. 1995).

Im Gegensatz zur eNOS steigt die Aktivität der iNOS während herzchirurgischer Operationen an. Bedingt wird dieser Effekt durch den inflammatorischen Reiz der HLM sowie die Reperfusion. Die exzessiv hohen NO-Konzentrationen können vor allem zu einer zusätzlichen Myokardschädigung während der Eingriffe führen. Das entstandene NO wirkt hierbei hauptsächlich proinflammatorisch, vasodilatierend und eben toxisch, da es zu Peroxynitrit reagieren kann. Lokal kann dies zu Apoptosen und Nekrosen bis hin zum zirkulatorischen Schock führen (Ruel et al. 2004, Sellke 1999).

Fazit ist, dass NO eine zentrale Position in der Vermittlung der vaskulären Homöostase einnimmt und dass herzchirurgische Eingriffe mit extrakorporaler Zirkulation zu deutlichen Veränderungen der NO-Bioverfügbarkeit und -Synthese führen. 


\subsection{Genom und Genpolymorphismus}

Als Genom wird die Gesamtheit aller Erbanlagen eines Lebewesens bezeichnet. Es umfasst den Gesamtbestand an Basenpaaren in der Desoxyribonukleinsäure (DNS, englisch DNA), sowohl den kodierenden als auch den nichtkodierenden Anteil. Die Sequenz des menschlichen Genoms kodiert die genetischen Informationen für die menschliche Physiologie, die individuellen Ausprägungen und enthält reichhaltige Informationen über die menschliche Evolution. Es besteht aus etwa 3,08 Milliarden Basenpaaren, wovon nur wenige Prozent ein Protein kodierendes Gen repräsentieren. Insgesamt besitzt der Mensch schätzungsweise 20.000 - 25.000 Gene (International Human Genome Sequencing Consortium 2004). Als Polymorphismus (molekulare Vielgestaltigkeit eines Individuums) bezeichnet man das Auftreten einer oder mehrerer Genvarianten (Unterschiede einer Nukleotidsequenz homologer Bereiche) innerhalb einer Population. Liegt die Häufigkeit des Auftretens einer Genvariante (d.h. die Allelfrequenz) über einem Prozent, so bezeichnet man das als Polymorphismus. Liegt diese drunter, so wird von einer Mutation gesprochen. Die Allelfrequenzen unterscheiden sich teilweise stark innerhalb verschiedener Ethnien (Abecasis et al. 2010).

Insgesamt lassen sich drei Arten von Polymorphismen unterscheiden. Der Einzelnukleotidpolymorphismus (Single Nucleotide Polymorphism, SNP), der Insertions- und Deletionspolymorphismus und der als Strukturvariante oder Kopienzahlvariante bezeichnete Polymorphismus (Copy number variation, CNV). Der Einzelnukleotidpolymorphismus, der oft auch als Punktmutation bezeichnet wird, ist die häufigste und stabilste Genvariante. Kennzeichnend hierfür ist der Austausch einer einzelnen Base innerhalb der DNA. Je nach Position des Polymorphismus kann die Qualität (Eigenschaft) und/oder die Quantität (Menge) des entstehenden Genproduktes verändert werden. Liegt z.B. der Polymorphismus innerhalb einer Promotorregion eines Gens, so verändert sich die Transkriptionsrate und damit die Expression des Gens, was zu einer quantitativen Veränderung führt. Liegt aber der Polymorphismus im kodierenden Bereich einer Gensequenz, kann das einen Aminosäureaustausch im resultierenden Protein zu Folge haben, wodurch es zu qualitativen Veränderungen im 
Genprodukt kommt. Posttranskriptionell können sich Polymorphismen auf das Spleißen eines Gens und auf die Stabilität der entstehenden Messenger-Ribonukleinsäure (mRNA) auswirken, wodurch es ebenfalls $\mathrm{zu}$ quantitativen Veränderungen des Genproduktes kommt. Unter einem Insertions- und Deletionspolymorphismus versteht man den Einbau bzw. den Verlust von mindestens einem Nukleotid. Dies kann dazu führen, dass für das Genprodukt keine Aktivität mehr nachweisbar ist. Kopienzahlvarianten sind Genduplikaturen bzw. Vervielfachungen und können das gesamte Gen betreffen (Abecasis et al. 2010, Levy und Strausberg 2008).

\subsection{1. eNOS T-786C-Polymorphismus}

Der in dieser Arbeit untersuchte T-786C-Polymorphismus betrifft die endotheliale NO-Synthase. Der Genlocus der eNOS befindet sich auf Chromosom 7q35 $\rightarrow 36$ und wurde 1993 entschlüsselt. Er beinhaltet 26 Exons und 25 Introns und erstreckt sich über 21 Kilobasen (kB) genomischer DNA (Marsden et al. 1993, Hingorani 2001). Bei den bis heute bekannten Polymorphismen, die das eNOS-Gen betreffen, handelt es sich fast ausschließlich um Einzelnukleotidpolymorphismen. Der T-786C-Polymorphismus liegt innerhalb der Promotorregion des eNOS-Gens die für die Expression des Gens verantwortlich ist und stellt ebenfalls einen Einzelnukleotidpolymorphismus dar. Hierbei kommt es zu einem Nukleotidaustausch von Thymin (T) gegen Cytosin (C) in Position 786 der 5' -flankierenden Region, wodurch es zu einer starken Reduktion (40 - 50\%) der Promotoraktivität und damit der Transkription kommt. Dadurch kommt es zu einer quantitativen Abnahme der entstehenden eNOS mit daraus resultierender Verminderung des gebildeten NO (Miyamoto et al. 2000, Rossi et al. 2003). Wie in den vorangegangenen Kapiteln bereits erwähnt, gelten verminderte NO-Konzentrationen und die daraus resultierende Endotheldysfunktion als Auslöser für die Atherosklerose. So wird klar, dass der T-786C-Polymorphismus Auswirkungen auf die Entwicklung bestimmter Formen der ischämischen Herzkrankheit und anderer Herz-KreislaufErkrankungen in verschiedenen Populationen hat (Dosenko et al. 2006, Rossi et al. 2003). Die Abnahme der Transkription wird durch die spezifische Bindung des replication proteins $A 1$ (RPA1) an das veränderte eNOS-Allel verursacht, wobei das RPA1 in diesem Fall als Repressor fungiert. Das RPA1 ist normalerweise als ein 
essentielles Protein bei der DNA-Reparatur, -Replikation und -Rekombination bekannt (Miyamoto et al. 2000, Rossi et al. 2003).

Einige Studien konnten bereits das vermehrte Auftreten von Myokardinfarkten und der koronaren Herzerkrankung (KHK) mit dem T-786C-Polymorphismus assoziieren. Hierbei waren die Homozygoten $\mathrm{C} / \mathrm{C}$-Allelträger stärker betroffen als die Heterozygoten T/C und die Homozygoten T/T-Allelträger (Wildtyp) (Dosenko et al. 2006, Nakayama et al. 2000, Rossi et al. 2003). Nakayama und seine Kollegen konnten dabei sogar den Polymorphismus als eigenständigen Risikofaktor für das Auftreten von Myokardinfarkten und Koronarspasmen detektieren. Dieser lag dabei deutlich höher als die sonst bekannten kausalen Risikofaktoren der KHK (Nakayama et al. 1999, Nakayama et al. 2000). Die in den japanischen Studien detektierten Koronarspasmen konnten bisher in keiner Studie an kaukasischen Patienten belegt werden, obwohl der T-786C-Polymorphismus häufiger bei Kaukasiern als bei Japanern nachweisbar ist. Eine Erklärung dafür könnte die unterschiedliche Ausprägung der Allelvarianten bei den verschiedenen Ethnien sowie eine dadurch bedingte unterschiedliche vasomotorische Reaktivität sein (Beltrame et al. 1999, Rossi et al. 2003). Klinische Studien zum Einfluss des Polymorphismus auf das Ergebnis nach koronarer Stentimplantation liegen ebenfalls vor. Demnach ist die In-Stent-Restenose sowie das Risiko einen Myokardinfarkt zu erleiden und das Versterben nach Stentimplantation bei homozygoten C-Allelträgern deutlich höher als die der anderen Genotypen (Gomma et al. 2002). Neben den direkten Auswirkungen des T-786C-Polymorphismus auf das eNOS-Gen scheinen auch die Aktivierungswege, die zu der Erhöhung der NO-Produktion führen, ebenfalls negativ durch diesen beeinflusst zu werden. So konnten Cattaruzza und Kollegen eine komplette Insensitivität gegenüber dem shear stress bei C/C-Allelträgern nachweisen. Hierbei zeigten T/C- und T/T-Träger jedoch eine adäquate Antwort auf den shear stress mit einer Erhöhung der eNOS, sowohl auf mRNA wie auch auf Proteinebene. Dieser Zustand begünstigt ebenfalls das Auftreten einer KHK, da die durch Scherkräfte induzierte NO-Produktion nicht nur der lokalen Blutdruckkontrolle dient, sondern auch effektiv die Arteriosklerose verhindert (Cattaruzza et al. 2004). Bei dem C/C-Genotyp kommt es ebenfalls zu einer 
abgeschwächten physiologischen Antwort auf die Hypoxie als Transkriptionsreiz, was zu einer inadäquaten Antwort des Endothels auf diesen Reiz führt (Rossi et al. 2003).

Da die Arteriosklerose nicht nur auf die Koronargefäße beschränkt ist, sondern es im gesamten Gefäßbaum zu einer Ausprägung kommen kann, konnten mehrere Studien die Assoziation zwischen den von uns untersuchten Polymorphismus und einem ischämischen Schlaganfall auf dem Boden einer Karotisstenose nachweisen. Demnach gilt das homozygote C-Allel als unabhängiger Risikofaktor für die Entstehung einer mittleren bis schweren Arteria carotis interna Stenose (Ghilardi et al. 2002). Da Karotisstenosen in Deutschland für etwa 50\% der Schlaganfälle pro Jahr verantwortlich sind, entspricht dies in etwa 30.000 Fällen (Mudra et al. 2006).

Bisher bleibt noch unklar ob der von uns untersuchte Polymorphismus einen Einfluss auf die kausalen Risikofaktoren der Arteriosklerose hat oder nicht. In einigen Studien konnte zwar eine Assoziation des T-786C-Polymorphismus mit der diabetischen Nephropathie nachgewiesen werden und dabei waren die homozygoten C-Allelträger häufiger in der Gruppe mit fortgeschrittener diabetischer Nephropathie vertreten als die beiden anderen Genotypen (Zanchi et al. 2000). Jedoch zeigten große Meta-Analysen in diesem Bereich eine insgesamt schwache Assoziation mit wenig Heterogenität. Solche Analysen sind aufgrund ihrer Einschluss- und Ausschlusskriterien und der erhobenen Datenmenge mit Vorbehalt zu interpretieren (Zeng et al. 2010). Im Tiermodell an diabetischen eNOS-Knockout-Mäusen lässt sich jedoch eine fortgeschrittene diabetische Nephropathie nachweisen (Nakagawa et al. 2007). Ebenso unklar ist der Zusammenhang zwischen dem T-786C-Polymorphismus und der arteriellen Hypertonie. So zeigen eNOS-Knockout-Mäuse (Huang et al. 1995) und gesunde Patienten, bei denen die eNOS gehemmt wird, einen deutlichen Hypertonus (Colomba et al. 2008). Jedoch präsentierten klinische Studien in diesem Bereich unterschiedliche Ergebnisse. So konnten Colomba und Mitarbeiter keine Assoziation aufzeigen (Colomba et al. 2008), andere Arbeitsgruppen wiesen jedoch eine deutliche Korrelation, vor allem der C-Allelträger nach (Hyndman et al. 2002). 
Fest steht, dass es eine deutliche Assoziation zwischen der Entstehung und den Folgen der Atherosklerose und dem von uns untersuchten Genpolymorphismus gibt. Ebenso zeigte sich, dass herzchirurgische Eingriffe mit einer extrakorporalen Zirkulation zu deutlichen Veränderungen der NO-Bioverfügbarkeit und -Synthese führen. Es ist daher auch sehr wahrscheinlich, dass eine durch den hier untersuchten Genpolymorphismus ohnehin verminderte eNOS-Aktivität mit verminderter NO-Produktion, einen starken Einfluss auf die Endothelfunktion und die postoperative Morbidität und Mortalität bei herzchirurgischen Patienten hat. So konnten Popov und Kollegen einen Zusammenhang zwischen dem T-786C-Polymorphimus und einer direkt peri/postoperativ erhöhten Mortalität in einer Subgruppe von herzchirurgischen Patienten aufzeigen. Hierbei waren homozygote C-Allelträger, wenn sie sich einer Notfalloperation unterziehen mussten, mit einer deutlich höheren Mortalität behaftet als TToder TC-Allelträger. Bei elektiven und dringlichen Operationen gab es keinen signifikanten Unterschied. Zusätzlich zeigte sich in der Gruppe der homozygoten C-Allelträger eine erhöhte Assoziation mit der peripheren arteriellen Verschlusskrankheit, ebenfalls ein Ausdruck einer fortgeschrittenen Arteriosklerose (Popov et al. 2010). In einer weiteren Studie konnte gezeigt werden, dass der T-786C-Polymorphismus ein Risikofaktor für die Entwicklung eines postoperativen Nierenversagens und den Einsatz einer Nierenersatztherapie bei herzchirurgischen Patienten darstellt. Auch hier waren die C-Allelträger häufiger betroffen und zeigten eine signifikante Reduktion der Kreatinin-Clearance und eine niedrigere Kreatinin-Clearance (Popov et al. 2009). Unterstützt werden die Ergebnisse von einer Studie, die den Einfluss des Polymorphismus auf die renale Hämodynamik und den arteriellen Blutdruck untersuchte und einen Unterschied zwischen den Genotypen feststellen konnte (Dengel et al. 2007). Dies ist eventuell darauf zurückzuführen, dass die verminderte NOProduktion bei C-Allelträgern die Mikrozirkulation in der Niere beeinflusst, indem es afferente Arteriolen reguliert (Wang und Wang 2000). Im Gegensatz dazu zeigte eine Studie von Liakopoulos und Mitarbeitern keinen Einfluss zwischen postoperativ aufgetretenen hämodynamischen Veränderungen und Organfunktionsstörungen bei herzchirurgischen Patienten. Jedoch war hier das Patientenkollektiv deutlich geringer und der Beobachtungszeitraum betrug nur 24 Stunden (Liakopoulos et al. 2006). 
Weitere Genassoziationsstudien die den klinischen Einfluss des T-786C-Polymorphismus auf herzchirurgische Patienten zeigen sind im Augenblick nicht vorhanden. Welchen klinischen Einfluss ein solcher Polymorphismus auf die Langzeitmortalität und -Morbidität haben könnte, ist bisweilen noch unklar. 


\subsection{Zielsetzung}

Wie bereits erwähnt, spielt NO eine essentielle Rolle innerhalb der Regulation der vaskulären Homöostase. Der von uns untersuchte T-786C-Polymorphismus führt zu einer starken Reduktion (40-50\%) der Promotoraktivität bei C-Allelträgern und damit der Transkription. Dadurch kommt es zu einer quantitativen Abnahme der entstehenden eNOS mit daraus resultierender Verminderung des gebildeten NO. So konnten bereits einige Studien den Zusammenhang zwischen dem Polymorphismus und Myokardinfarkten, der KHK und Koronarspasmen aufzeigen.

Obwohl herzchirurgische Eingriffe mit extrakorporaler Zirkulation zu deutlichen Veränderungen der NO-Bioverfügbarkeit und -Synthese führen, ist der klinische Einfluss des T-786C-Polymorphismus auf diese Patientengruppe kaum untersucht worden. Popov und Kollegen konnten zwar in ihrer Studie, die gleichzeitig die vorangegangene Studie $\mathrm{zu}$ der hier durchgeführten Arbeit darstellt, eine erhöhte Mortalität bei homozygoten Trägern des C-Allels und Notfalloperationen nachweisen. Jedoch zeigten die anderen Subgruppen hinsichtlich der Mortalität keine signifikanten Unterschiede bezogen auf die Genotypen. Da herzchirurgische Patienten ohnehin eine erhöhte Mortalität nach Notfalloperationen aufweisen, die Subgruppe eine relativ geringe Fallzahl aufwies und der Polymorphismus zu einer dauerhaften Verringerung der eNOS-Aktivität beiträgt, könnte es eine deutlichere Assoziation in den Subgruppen im Langzeitverlauf geben.

Ziel der Studie war es, die klinische Relevanz des T-786C-Polymorphismus auf die Mortalität und Morbidität im Langzeitverlauf von Patienten nach herzchirurgischen Eingriffen mit einer extrakorporalen Zirkulation zu untersuchen. Damit ließe sich ableiten, ob der Polymorphismus genug Pathogenität zeigt, um beispielweise als eigenständiger Risikofaktor für eine erhöhte Mortalität nach herzchirurgischen Operationen zu gelten. Dadurch könnte er als präoperativer genetischer Marker für die Risikoadjustierung dienen. Zusätzlich könnte dies aber neue peri- und postoperative Behandlungskonzepte für betroffene Patienten ermöglichen. 


\section{Material und Methoden}

\subsection{Patientenkollektiv und Studienkonzept}

Das Patientenkollektiv der prospektiv durchgeführten Studie umfasste 500 herzchirurgische Patienten kaukasischer Herkunft, die sich im Zeitraum November 2005 bis Dezember 2006 in der Abteilung der Thorax-, Herz- und Gefäßchirurgie (THG) der Universitätsmedizin Göttingen (UMG) (Direktor: Prof. Dr. med. Dipl.-Phys. F.A. Schöndube) einer Herzoperationen unterziehen mussten. Alle durchgeführten Operationen wurden an einer Herz-Lungen-Maschine durchgeführt und umfassten Bypass-, Klappenvitien- und Kombinationseingriffe. Zusätzlich wurden auch Eingriffe an den großen herznahen Gefäßen sowie mehrfach Klappeneingriffe durchgeführt. Es wurden sowohl weibliche als auch männliche Patienten eingeschlossen und das Mindestalter für die Teilnahme betrug 18 Jahre. Da neben dem direkten postoperativen Einfluss des Polymorphismus auf herzchirurgische Patienten von vornerein eine Langzeitstudie geplant war, wurden Patienten älter als 80 Jahre und Patienten mit einer vorbekannten Neoplasie, aufgrund des unvorhersehbaren Ausgangs ihrer malignen Erkrankung bzw. des hohen Alters, von der Studie ausgeschlossen. Es wurden sowohl elektive als auch dringliche und Notfalloperationen in die Studie einbezogen. Die postoperative intensivmedizinische Behandlung der Patienten erfolgte auf den Intensivstationen des Zentrums für Anästhesiologie, Rettungs- und Intensivmedizin der UMG (Direktor: Prof. Dr. med. M. Quintel). Die anschließende stationäre Versorgung der Patienten bis zum Zeitpunkt der Entlassung wurde erneut von den Mitarbeitern der THG durchgeführt.

Um den klinischen Einfluss des von uns untersuchten eNOS T-786C-Polymorphismus auf die Langzeitmortalität und -Morbidität bei herzchirurgischen Patienten zu prüfen, erfolgte eine erneute Nachverfolgung dieses Patientenkollektivs nach Ablauf von etwa fünf Jahren. Für die Datenerhebung wurde ein Fragebogen erstellt, der anschließend an die behandelnden Hausärzte versendet wurde. Die somit gewonnen Daten wurden ausgewertet und in eine hierfür vorgesehene Datenbank eingetragen. Die Patientenaufklärung und Einwilligung der Patienten in die Studie 
erfolgte durch die Kollegen, die den direkten peri-/postoperativen Einfluss des T-786C-Polymorphismus untersuchten (Henker 2011, Popov et al. 2010). Diese beinhaltete die Studienziele, die Erhebung, Auswertung und Speicherung der Patientendaten, die Freiwilligkeit der Teilnahme, die Notwendigkeit einer Blutentnahme zur Genanalyse sowie eine eventuelle erneute Datenerhebung im Langzeitverlauf. Zusätzlich wurde den Patienten unmissverständlich mitgeteilt, dass sie zu jedem Zeitpunkt ohne Angaben von Gründen aus der Studie austreten könnten. Erst nach der schriftlichen Einverständniserklärung der Patienten wurden diese in die Studie eingeschlossen und eine Blutentnahme durchgeführt (Siehe Anlage). Die Studie wurde von der Ethikkommission der Georg-August-Universität geprüft und genehmigt (siehe Anlage, Antragsnummer 30/7/05).

\subsection{Datenerhebung}

Für die Datenerhebung wurde ein Fragebogen erstellt und anschließend an die behandelnden Hausärzte der Studienteilnehmer gesendet. Die von den Hausärzten beantworteten und zurückgesendeten Fragebögen wurden ausgewertet und in die seit der Vorgängerstudie bestehende Datenbank eingefügt. Die Datenbank wurde eigens für die Polymorphismusstudien auf der Basis von Microsoft ${ }^{\circledR}$ Access und der Programmiersprache Microsoft ${ }^{\circledR}$ Visual Basic erstellt und genügt dem Standard für rationale Datenbanken. Um eine möglichst vollständige Nachverfolgung zu erhalten, folgte bei Ausbleiben der Antwort ein erneutes Anschreiben der Hausärzte. Bei erneutem Ausbleiben der Antwort, erfolgte im nächsten Schritt die direkte telefonische Kontaktaufnahme mit dem Patienten. Hierbei wurde der komplette Fragebogen zusammen mit dem Patienten am Telefon bearbeitet und die Daten so vollständig wie möglich erhoben. Dadurch, dass manche Patienten in der Zwischenzeit verzogen sind oder den Hausarzt wechselten, war bei 101 Patienten eine Datenerhebung zunächst nicht möglich. Bei diesen Fällen wurde in einem letzten Schritt das zuständige Einwohnermeldeamt, unter der Berufung auf $\S 21(2)$ Melderechtsrahmengesetz (MRRG), kontaktiert, um so Informationen bezüglich der Mortalität zu erhalten. $\S 21$ (2) MRRG bezieht sich auf die erweiterte Melderegisterauskunft und erlaubt die Datenweitergabe an Personen bzw. Institutionen, die ein berechtigtes Interesse 
glaubhaft machen. Neben normalen Informationen wie den Vor- und Familiennamen, Anschrift usw., dürfen auch Daten wie Tag des Ein- und Auszugs sowie Sterbetag und -ort weitergegeben werden. Gesichert ist auch, dass der Betroffene über die Erteilung der Auskunft unter Angaben des Datenempfängers unverzüglich unterrichtet wird. Erst durch diesen Schritt konnte eine vollständige Nachverfolgung erreicht werden.

Zusätzlich wurde auf die bereits in der Datenbank enthaltenen Daten aus der vorangegangenen Studie, die den direkten peri-/postoperativen Einfluss untersucht hatte, zurückgegriffen (Henker 2011, Popov et al. 2010). Dadurch ließ sich die Datenerhebung in zwei Bereiche gliedern. Auf der einen Seite die vorangegangene Datensammlung und auf der anderen Seite die aktuelle Datenerhebung.

\subsubsection{Vorangegangene Datenerhebung}

Da die hier vorgelegte Arbeit eine Folgestudie als Langzeitverlauf darstellt, wurde auf die entsprechenden Daten aus der Vorgängerstudie (Henker 2011, Popov et al. 2010) zurückgegriffen und diese teilweise übernommen. Die übernommenen Daten beinhalteten sowohl präoperative wie auch intraoperative und postoperative Daten.

Bei den präoperativen Daten wurden neben den allgemeinen Patientendaten wie Name, Geburtsdatum, Adresse, Telefonnummer, Geschlecht, betreuender Hausarzt, Größe und Gewicht auch die studienspezifische Patientennummer zu Anonymisierung übernommen. Diese vereinfachte die Zuordnung der neu erhobenen Daten und erlaubte eine schnellere Auswertung dieser. Des Weiteren wurden der Operations- sowie der Todeszeitpunkt dokumentiert, um so eine möglichst zeitgenaue Nachuntersuchung zu gewährleisten.

Bei den intraoperativen Daten waren die Dringlichkeit des Eingriffs (elektiv, dringlich, Notfall) sowie die durchgeführte Operation von Bedeutung und wurden ebenfalls mit übernommen. Als dringliche Eingriffe wurden hierbei Operationen definiert, die innerhalb einer Woche seit Hospitalisierung und Indikationsstellung des Patienten stattfanden. Als Notfalloperationen galten alle Eingriffe, die sofort und außerhalb des normalen Operationsplans durchgeführt wurden. Die durchgeführten 
Eingriffe gliederten sich in alleinige Bypassoperationen, alleinige Klappenoperationen, Kombinationseingriffe und andere Eingriffe.

Bei den postoperativen Daten wurden die direkte peri-/postoperative Mortalität und die Verteilung der Genotypen übernommen, da diese das Gesamtkollektiv betrafen. Die Mortalität wurde damals als innerhalb des Krankenhausaufenthaltes festgestellter Tod definiert, egal welcher Ursache. Für die Genotypisierung wurde initial postoperativ eine Blutentnahme aus einem für die Operation benötigten Zugang (zentraler Venenkatheter, arterieller Katheter) durchgeführt. Das EDTA-gepufferte (Ethylendiamintetraessigsäure) Vollblut wurde anschließend bei $-20^{\circ} \mathrm{C}$ eingefroren und für die Bestimmung der Genotypen konserviert. Im Anschluss erfolgte in mehreren Einzelschritten (DNAIsolierung, Polymerase-Kettenreaktion (PCR) und Gelelektrophorese) die Analyse der Genotypen. Die für die einzelnen Patienten erhobenen Daten wurden dann entsprechend in der Datenbank eingefügt und gesichert (Henker 2011, Popov et al. 2010).

\subsubsection{Aktuelle Datenerhebung}

Um eine möglichst vollständige Beantwortung des Fragebogens zu ermöglichen sowie eine adäquate Kontaktaufnahme mit den Hausärzten herzustellen, wurde in einem ersten Schritt ein Anschreiben entworfen, welches dem Fragebogen beigelegt wurde. Das Anschreiben enthielt Informationen bezüglich der Studie, Studienziele, Einwilligung des Patienten in die Studie, sowie eine Mitteilung zur Erlaubnis der erneuten Datenerhebung bezüglich des aktuellen Gesundheitszustandes über die Hausärzte. Ferner wurde um Mithilfe sowie um eine möglichst vollständige Beantwortung gebeten, den nur so könnten Daten generiert werden die wissenschaftlich verwertbare Aussagen wiederspiegeln. Um eine Transparenz zu ermöglichen, wurde neben dem Vermerk der Genehmigung durch die zuständige Ethik-Kommission mit Angabe der Antragsnummer, eine Möglichkeit zu einer telefonischen Rücksprache bei Unklarheiten und Fragen eingeräumt. Den Hausärzten, die trotz des Anschreibens weiterhin Zweifel und Bedenken an der Datenfreigabe hatten, wurde die Einsicht in die Einverständniserklärung des sie betreffenden Patienten erlaubt sowie die Genehmigung der Ethik-Kommission vorgelegt. Dadurch wurde eine mögliche Nichtbeantwortung aufgrund von Zweifeln verhindert und eine noch größere Transparenz ermöglicht. 


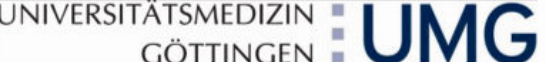

Klinik und Poliklinik für Thorax-, Herz- und Gefäßchirurgie

Prof. Dr. med. Dipl.-Phys. F.A. Schöndube

Studienleiter: Dr. med. A.-F. Popov

\section{Zentrum Anaesthesiologie, Rettungs- und Intensivmedizin}

Prof. Dr. med. M. Quintel

Studienleiter: PD Dr. med. J. Hinz

Sehr geehrte Kolleginnen und Kollegen,

im Rahmen der Studie „Die Bedeutung der Gen-Polymorphismen Endothelin-1 G198T, Endothelin-T1370G (ET-1), e Nitric Oxide Synthase G894T und e Nitric Oxide Synthase T786C (eNOS) für das Auftreten und den Schweregrad des Lungenversagens. " benötigen wir Information zu Ihrem Patient/Patienten

Ihr Patient/Patientin hat im Jahr 2006 an der obigen Studie teilgenommen und sich bereit erklärt, dass wir uns im Verlauf mit seinem Hausarzt in Kontakt setzen, um die neusten Daten zu seinen/ihren Krankheitsverlauf zu erhalten.

Daher sind wir auf Ihre Mithilfe angewiesen und hoffen, dass Sie uns mit den entsprechenden Daten ein „Follow up“ der Studie ermöglichen. Sie geben uns damit die Möglichkeit, Kenntnisse auf dem Gebiet des Lungen- und des Organversagens nach herzchirurgischen Operationen mit Herz-Lungenmaschine zu erweitern.

Wir möchten Sie bitten, den beigefügten Fragebogen soweit wie möglich zu beantworten, da nur durch vollständig beantwortete Fragen wissenschaftlich verwertbare Aussagen gemacht werden können.

Bitte senden Sie den ausgefüllten Fragebogen unter der Faxnummer: 0551/398375 mit dem Betreff: „Polymorphismus-Studie“ schnellstmöglich an uns zurück.

Bei Fragen stehen wir natürlich jederzeit telefonisch zur Verfügung.

Die Studie wurde von der hiesigen Ethik Kommission mit der Antragsnummer: 30/7/05 genehmigt. Vielen Dank für Ihre Mithilfe.

Mit freundlichen kollegialen Grüßen,

$\begin{array}{ll}\text { Priv.- Doz. Dr. med. J. Hinz } & \text { Tel: } 0551 / 3922995 \\ \text { Dr. med. A.-F. Popov } & \text { Tel: } 0551 / 3914691 \\ & \\ \text { Doktoranden: } & \text { Tel: } 0176 / 24196483 \\ \text { Hr. Christan Bireta } & \text { Tel: } 0176 / 24869426 \\ \text { Fr. Christina Lipke } & \end{array}$

Abbildung 1: Anschreiben an die Hausärzte 
Nach Fertigstellung des Anschreibens erfolgte die Entwicklung und Erstellung des Fragebogens. Dieser wurde anschließend mit dem Anschreiben an die zuständigen Hausärzte versendet. Aufgrund der vorliegenden peri-/postoperativen Mortalität von $8,2 \%$ in der initialen Studie wurde der Fragebogen nur an die noch 459 übriggebliebenen Patienten bzw. an deren Hausärzte verschickt. Ziel des Fragebogens war es, eine möglichst vollständige Datenerhebung bezüglich des Gesundheitszustandes der einzelnen Patienten im Langzeitverlauf bezogen auf die Mortalität und Morbidität $\mathrm{zu}$ erhalten und $\mathrm{zu}$ eruieren welchen klinischen Einfluss der von uns untersuchte Polymorphismus auf das Patientenkollektiv ausüben würde. So gliederte sich der von uns erstellte Fragebogen in zwei Bereiche, wobei offene und geschlossene Fragen verwendet wurden. Der erste Abschnitt befasste sich mit der Mortalität der Patienten und der zweite mit ihrer Morbidität, wobei hier die einzelnen Organsysteme genauer eruiert wurden. Alle im Fragebogen enthaltenen Fragen zielten auf eine mögliche Detektion einer Prävalenz bei bestimmten Genotypen bezüglich der Mortalität und Morbidität.

Die Fragen zur Mortalität beinhalteten zwei wichtige Aspekte, zum einen den Todeszeitpunkt und zum anderen die Todesursache. Der Todeszeitpunkt wurde gewählt, um Unterschiede in der Überlebenszeit bezogen auf die Genotypen zu erkennen, falls welche vorhanden seien. Bei der Todesursache lag die Bedeutung darin, ein eventuell gehäuftes Auftreten von Ursachen die zum Tode führten zu detektieren und diese in Bezug mit dem untersuchten Polymorphismus zu setzen. Um zu klären ob dieser hierbei einen klinischen Einfluss ausüben könnte.

Den Fragen zur Mortalität folgte der Morbiditätsabschnitt. Dieser beinhaltete spezifische Fragen zu den einzelnen Organsystemen und ihrer eventuell neu aufgetretenen Erkrankungen und gliederte sich in vier Teilabschnitte. Die Auswahl der Organsysteme und der verwendeten Fragen richtete sich nach den Auswirkungen einer verminderten NO-Menge auf diese und der möglichen Assoziation mit dem dafür verantwortlichen T-786C-Polymorphismus. Erkrankungen und Organsysteme die von vornerein keine Assoziation bzw. eine Unabhängigkeit von der vorhandenen NO-Menge aufzeigen 
würden, wurden nicht eruiert. Zu den Organsystemen die erfragt wurden, gehörten das zentrale Nervensystem (ZNS), die Lunge, die Niere und das Herz.

Den ersten Teilabschnitt bildete das ZNS, mit den Fragen bezüglich eines neu aufgetretenen Apoplex oder einer Hirnblutung nach stationärer Entlassung. Bei einer bejahenden Antwort sollten die Hausärzte noch zusätzlich das Datum des Ereignisses angeben, falls dieses bekannt sei. Dieses galt auch für alle anderen Fragen die bejahend beantwortet wurden.

Der zweite Themenkomplex setzte sich aus Fragen zu Erkrankungen des pulmonalen Systems zusammen. Hierbei war es wichtig, Informationen bezüglich neu aufgetretener chronischer obstruktiver Lungenerkrankung (COPD) und Asthma zu erhalten. Außerdem sollten Angaben bezüglich einer erneuten Beatmung, den Beatmungsgrund und die Beatmungsdauer gemacht werden.

Im anschließenden dritten Abschnitt wurden die Werte $\mathrm{zu}$ den Retentionsparametern (Kreatinin und Harnstoff) erfragt. Hierbei sollten zu einem der aktuellste und zum anderen der maximalste Wert, der im Verlauf der letzten drei Jahre gemessen worden ist, genannt bzw. angegeben werden. Zusätzlich wurde ermittelt, ob der Patient seit der stationären Behandlung ein Nierenersatzverfahren (z.B. eine Hämodialyse, Hämofiltration usw.) benötigte oder nicht.

Der letzte, und aufgrund der zentralen Position des NO im Herz-Kreislauf-System wichtigste Teilabschnitt beinhaltete Fragen $\mathrm{zu}$ kardialen Ereignissen bzw. Erkrankungen. Zunächst sollten Angaben zu erneutem Auftreten von Angina pectorisBeschwerden und einem erneuten Myokardinfarkt gemacht werden. Hierdurch wollten wir ein mögliches Voranschreiten der Arteriosklerose, die durch eine eventuell verminderte NO-Menge bedingt wurde, detektieren. Falls vorhanden und durchgeführt, sollte ebenfalls eine Kopie des Herzkatheterbefundes mitgeschickt werden. Anschließend folgten Fragen $\mathrm{zu}$ neu aufgetretenen Rhythmusstörungen und Vorhofflimmern. Zusätzlich sollten die Hausärzte Angaben zu eventuell vorhandenen Echokardiographiebefunden machen. Dabei genügten Angaben zu der Ejektionsfraktion (EF) und des pulmonalen arteriellen Mitteldrucks (PAPmean, mean pulmonary arterial pressure), beides Werte die die Herzfunktion der Patienten widerspiegeln. Abschließend wurden noch Fragen bezüglich einer Re-Intervention am Herzen und die Art der Re-Intervention (z.B. Stent, Re-Operation, usw.) gestellt. 
Betreff: Polymorphismus-Studie (Fax: 0551/398375)

\section{UNIVERSITÄTSMEDIZIN
GÖTTINGEN ": UMG}

Studien-Nr.:

Name des Patienten:

Geburtsdatum des Patienten:

Ist der Patient/die Patienten verstorben? Falls ja, nennen Sie uns bitte die Todesursache und das Todesdatum.

Erfolgte eine erneute Hospitalisierung (postoperativ) aufgrund pulmonaler oder kardialer Genese (wenn ja, bitte mit Datum)?

\section{$\underline{\text { ZNS }}$}

Hatte der Patient nach der stationären Entlassung einen:
- Apolex:
Ja:
, (Datum)
Nein:
- Blutung im ZNS:
a:_ (Datum)
Nein:

\section{Lunge:}

Leidet der Patient unter (postoperativ):

\begin{tabular}{|c|c|c|}
\hline COPD: & $\mathrm{Ja}: \_$, (Datum) & Nein: \\
\hline Asthma: & Ja: $\quad$, (Datum) & Nein: \\
\hline
\end{tabular}

Wurde der Patient nach der stationären Entlassung beatmet?

Ja:__ (Datum)___ N _ _ _ _ _ _ _

Falls ja, wie lange und warum hat die Beatmung stattgefunden?

Abbildung 2: Fragebogen Seite 1 
Betreff: Polymorphismus-Studie (Fax: 0551/398375)

Studien-Nr.:

UNIVERSITÄTSMEDIZIN $=\mathbf{M G}$
GÖTTINGEN $=\mathbf{M G}$

Name des Patienten:

Geburtsdatum des Patienten:

\section{Niere:}

Bitte nennen Sie uns die Harnstoff und Kreatininwerte des Patienten mit Einheit.

(Wir benötigen den Maximalwert der letzten 3 Jahre als auch den aktuellsten Wert)

Kreatinin: $\max$ : (Datum): aktuell: (Datum): Einheit

Harnstoff: max: (Datum): , aktuell: (Datum): Einheit

Benötigte der Patient nach der stationären Behandlung und/oder aktuell ein Nierenersatzverfahren?

Ja: , (Datum)

Nein:

\section{Herz:}

Hatte der Patient nach der stationären Behandlung:

- einen Myokardinfarkt:

Ja: , (Datum)

Nein:

- eine Angina pectoris:

Ja: , (Datum)

Nein:

- Vorhofflimmern:

Ja: , (Datum)

Nein:

- Rhythmusstörungen :

Ja: , (Datum)

Nein:

- Re-Intervention am Herzen: Ja: , (Datum)

Nein:

- Art der Re-Intervention (z.B. Operation, Stent):

Als letztes möchten wir Sie noch bitten, uns Befunde zu den folgenden Untersuchungen mitzuteilen, falls diese innerhalb der letzten 3 Jahre durchgeführt worden sind.

Echokardiografie: $\quad \mathrm{EF}(\%)$ : Datum: $\mathrm{PAP}_{\text {mean }}(\mathrm{mmHg})$ : Datum:

Herzkatheterbefund, wenn vorhanden in Kopie mit Datum:

Abbildung 3: Fragebogen Seite 2 
Parallel zu der hier vorgelegten Arbeit, erfolgte aus der gleichen Arbeitsgruppe Prof. Dr. med. J. Hinz / PD Dr. med. A. Popov die Durchführung einer weiteren Studie durch Frau Lipke, die den "Einfluss des eNOS-G-894T-Polymorphismus auf die 5-Jahres-Mortalität und -Morbidität kardiochirurgischer Patienten" untersuchte. Der Zeitaufwand, für die Durchführung der einzelnen Arbeitsschritte der Studien, betrug 30 Wochenstunden für beide Doktoranden über einen Zeitraum von etwa eineinhalb Jahren (Juni 2010 - Januar 2012). Alle für die Studien nötigen Arbeitsschritte (Datenerhebung, Datenauswertung, statistische Analyse sowie Erzeugung der Tabellen und Graphen), wurden zu gleichen Anteilen von den daran beteiligten Doktoranden (Bireta / Lipke) in kollegialer Zusammenarbeit durchgeführt.

\subsection{Statistische Analyse}

Die statistischen Berechnungen erfolgten mit der Software STATISTIKA (Statsoft Inc. Tulsa, OK, USA). Bei allen statistischen Verfahren wurde eine Irrtumswahrscheinlichkeit $\mathrm{p}<0,05$ für den Alpha-Fehler als signifikant angenommen. Die Überprüfung der Ergebnisse auf die Normalverteilung erfolgte mit dem Kolmogorov-Smirnov-Test. Bei Annahme der Normalverteilung wurde die deskriptive Statistik als Mittelwert \pm Standardabweichung ermittelt. Bei Ablehnung der Normalverteilung durch den Kolmogorov-Smirnov-Test wurde die deskriptive Statistik als Median und Bereich angegeben. Bei nicht normalverteilten Daten wurde der Wilcoxon-matched-pair-Test, der Mann-Whitney-U-Test oder der Kruskal-Wallis-Test angewendet. Bei normalverteilten Werten wurde der T-Test verwendet. Kategoriale Variablen wurden als prozentualer Anteil der Grundgesamtheit angegeben. Die Überprüfung auf signifikante Unterschiede zwischen den Gruppen erfolgte in einer Feldertafel mit dem einseitigen Chi-Quadrat-Test. Für kleine Fallzahlen wurde mit dem Exakten Fisher-Test untersucht. Das kumulative Überleben wurde mit einer Survivalanalyse nach Kaplan-Meier und einem Log-rank-Test untersucht. Eine Korrektur nach Bonferroni wurde nicht durchgeführt. 


\section{Ergebnisse}

\subsection{Auswertung und Analyse des Patientenkollektivs}

Basierend auf den Ergebnissen der Dissertation von Herrn Henker und der daraus resultierenden Publikation von Herrn Popov, wurde auf entsprechende Daten und Tabellen zurückgegriffen und diese teilweise übernommen. Diese Daten wurden bereits ausführlich diskutiert. Sie sind für die hier durchgeführte Arbeit jedoch essentiell, da die anschließenden Ergebnisse teilweise darauf aufbauen und $\mathrm{zu}$ ihnen in Bezug gesetzt werden. $\mathrm{Zu}$ den übernommen Daten gehören die Genotypen und Allelverteilung, Altersund Geschlechtsverteilung sowie Operationszeitpunkt und Art der Eingriffe. Diese Daten stellen die Grunddaten für die hier durchgeführte Arbeit dar und sind deshalb erneut in dieser Arbeit aufgeführt. Zusätzlich wurde die direkte peri-/postoperative Mortalität übernommen, um sie in Bezug zu der Mortalität nach fünf Jahren setzten zu können.

Das gesamte Patientenkollektiv umfasste 500 Patienten, die sich im Zeitraum November 2005 bis Dezember 2006 einer Herzoperation unterzogen hatten. Der Nachbeobachtungszeitraum betrug fünf Jahre. Die direkte peri-/postoperative Mortalität betrug 8,2\% ( $\mathrm{n}=41)$ (Henker 2011, Popov et al. 2010), somit konnten in die Langzeitnachverfolgung 459 Patienten eingeschlossen werden. Nach dem zweimaligen Anschreiben der Hausärzte bezüglich der noch 459 verbliebenen Patienten wurden 329 Fragebögen beantwortet an uns zurückgesendet. Damit konnte zunächst eine Nachverfolgung von 71,7\% erreicht werden. Im zweiten Schritt erfolgte die telefonische Kontaktaufnahme mit dem Patienten. Hierdurch konnten weitere 29 Patienten erfasst werden, wodurch weitere $6,3 \%$ an Daten generiert werden konnten. Im Anschluss erfolgte die Einholung der Auskunft über die Einwohnermeldeämter, wodurch die letzten 101 Patienten erfasst wurden. Damit konnten noch weitere $22 \%$ an follow-upDaten eruiert werden. Somit betrug das Gesamtfollow-up in unserer Studienpopulation nach Abschluss aller Maßnahmen hinsichtlich der Mortalität 100\%. Im Bereich der Morbidität konnten, aufgrund des ungenügenden Datenrücklaufs, nur unzureichende 
Daten gewonnen werden, so dass keine klinisch relevanten Aussagen gemacht werden konnten.

Um die Nachverfolgungsdauer von fünf Jahren $\mathrm{zu}$ gewährleisten, erfolgte zunächst die Definition des Nachbeobachtungszeitraums. Hierzu wurde aus der initialen Studie der Operationszeitpunkt als Startpunkt übernommen, um so eine einheitliche Definition des ersten Messpunktes zu erhalten. Als Endpunkt der Datenerhebung wurde das Datum des letzten von uns durchgeführten Patientenkontakts gewählt. Somit wurde bei dem Endpunkt ebenfalls ein einheitlicher Messpunkt definiert. Dadurch konnte ein einheitlicher Nachbeobachtungszeitraum ermittelt werden.

Um statistische Aussagen hinsichtlich der Überlebenszeit (gelebte Tage nach Operation) und der Überlebensraten mittels Kaplan-Meier-Kurven treffen zu können, wurde bei verstorbenen Patienten zusätzlich der bekannte Todeszeitpunkt bzw. das Todesdatum als weiterer Messpunkt eingetragen. Bei Patienten die während des Nachbeobachtungszeitraums lebten, wurde der bereits vorhandene Endpunkt erneut übernommen. Somit konnten die Überlebenszeit sowie die Überlebensraten zeitlich dokumentiert werden. Diese Daten werden in Kapitel 3.5 ausführlich besprochen.

Die Auswertung der Patienten zeigte erwartungsgemäß zwei Peaks in dem Nachverfolgungszeitraum, die sowohl mit der initialen (Henker 2011) wie auch der neuen Arbeit korrelierten. $\mathrm{Zu}$ einem wurde ein geringer Anteil an Daten direkt peri/postoperativ erhoben. Zum anderen zeigte sich ein weiterer Peak, mit dem Großteil der Daten, während des follow-up Zeitraums (60 - 72 Monate nach Operation). Zu den Daten, die direkt peri/postoperativ durch Herrn Henker erhoben wurden, zählten Patienten die während der initialen Behandlung verstorben sind. Daten die während unseres follow up erhoben wurden, werden in dieser hier durchgeführten Arbeit erläutert.

Um die Dauer der Nachverfolgung differenzierter darzustellen, wurde in den nachstehenden Grafiken die Anzahl der Patienten gegen das Datum der Datenerhebung (Endpunkt), jeweils in drei Monatsschritten gruppiert, aufgetragen. Hierbei zeigte sich sowohl bei dem Gesamtkollektiv wie auch bei den einzelnen Genotypen die zu erwartende Verteilung mit den zwei Peaks. 


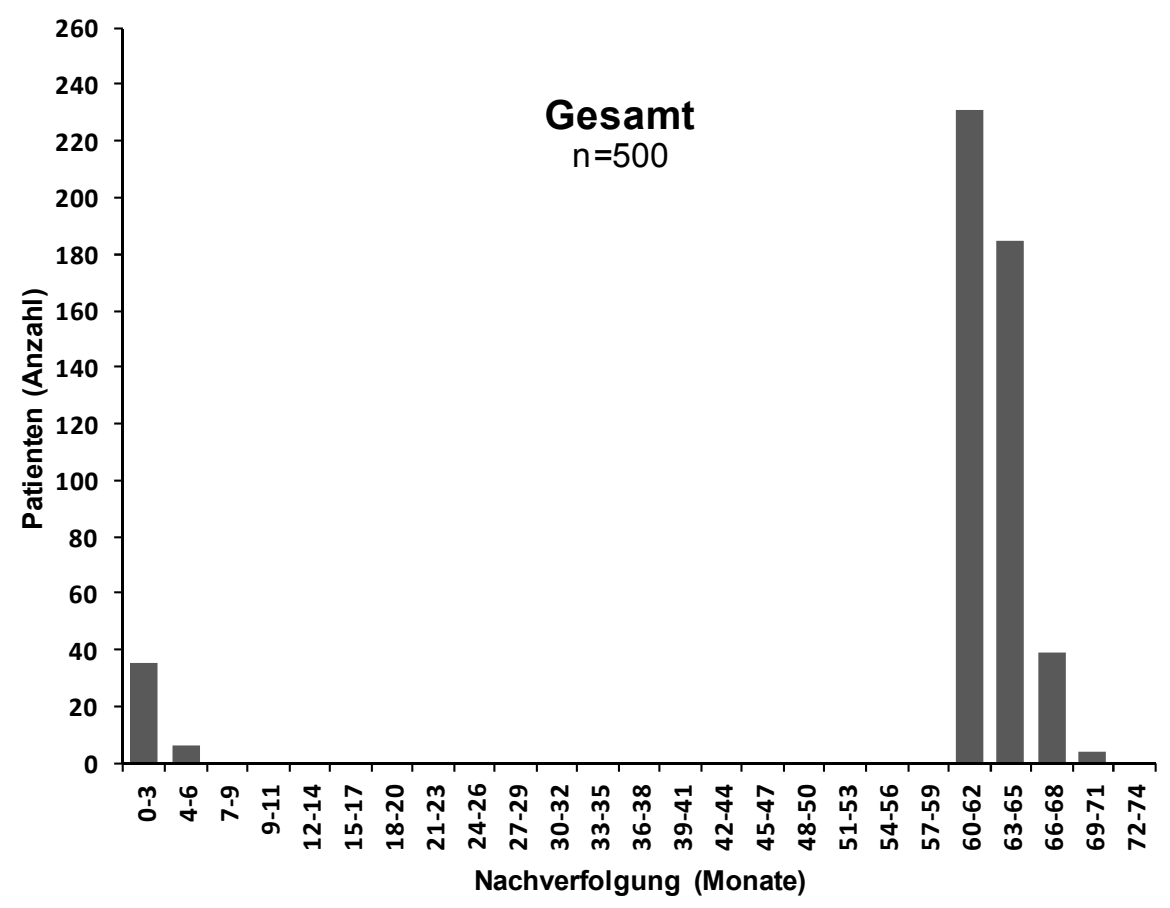

Abbildung 4: Detaillierte Übersicht der Nachverfolgungszeit des Gesamtkollektivs

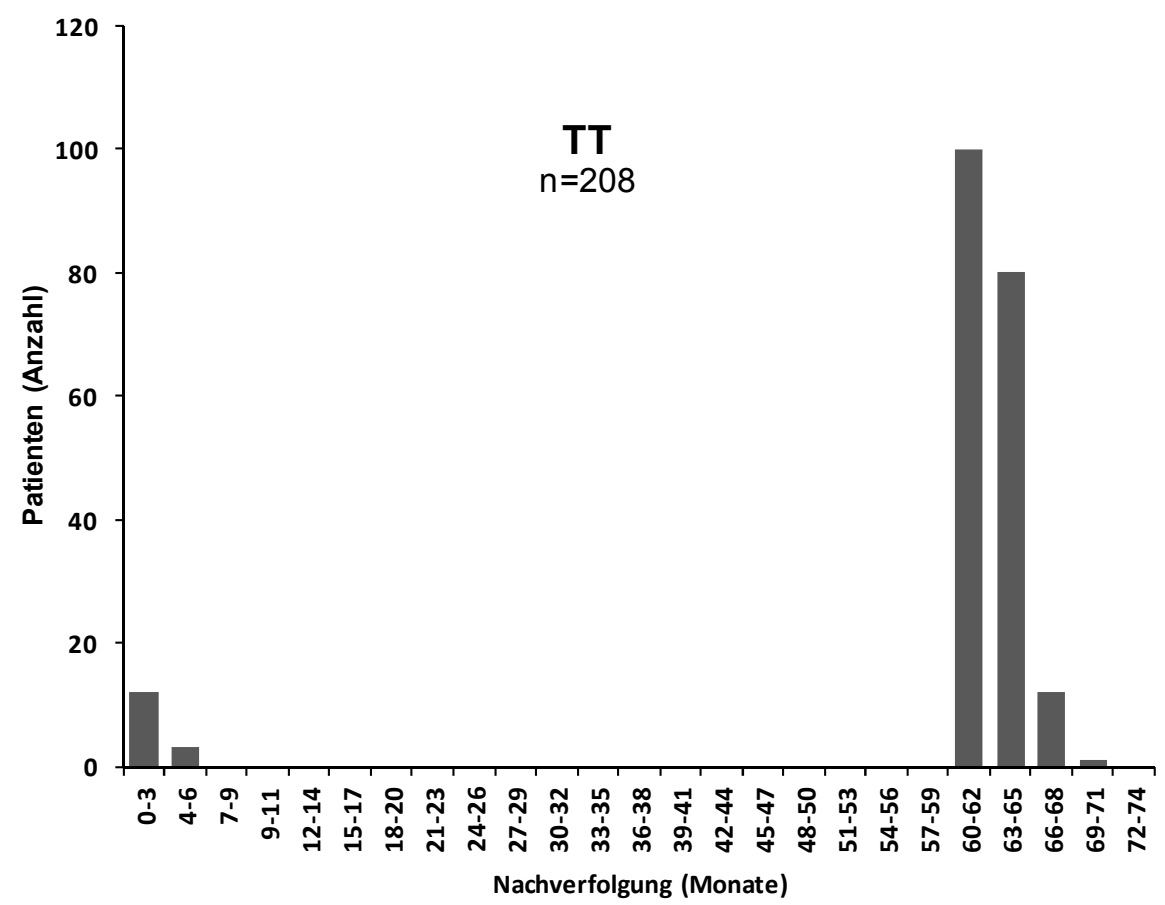

Abbildung 5: Detaillierte Übersicht der Nachverfolgungszeit des TT-Genotyp 


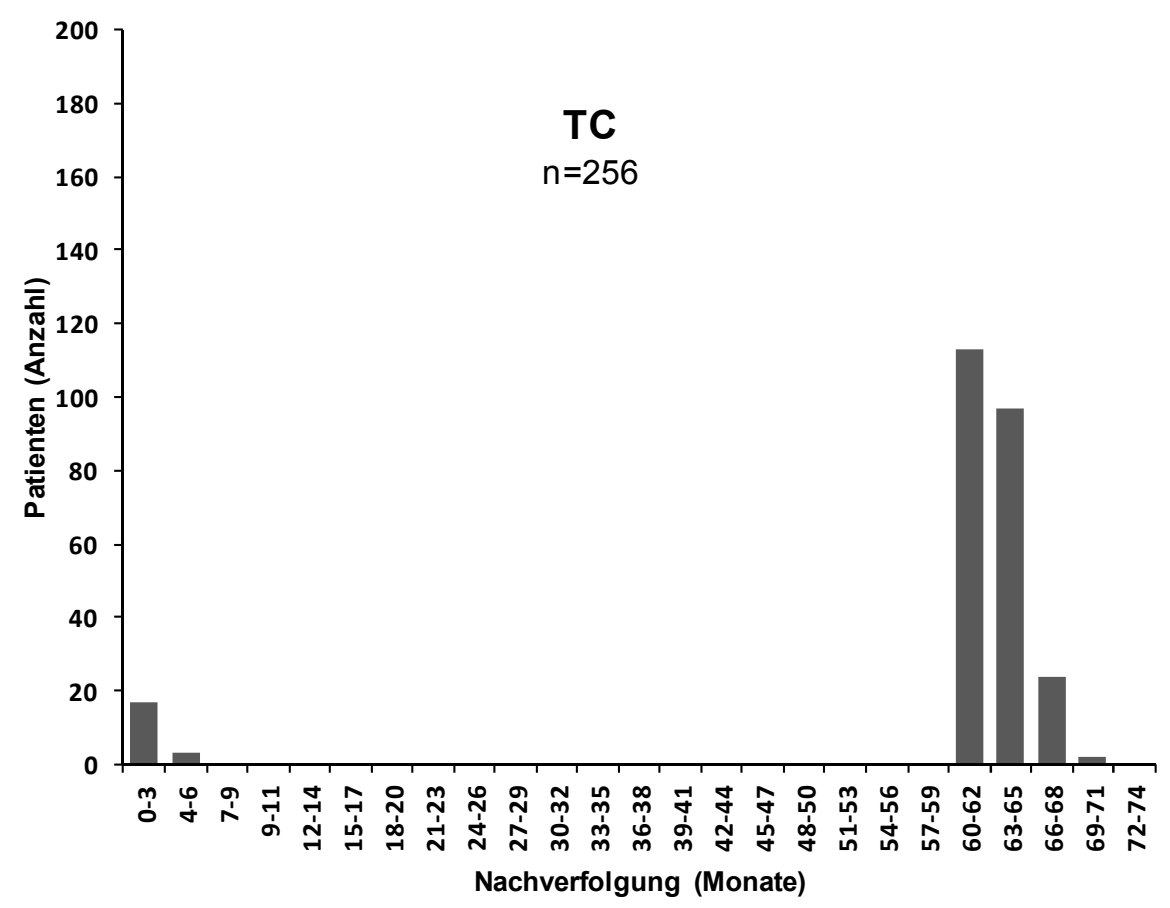

Abbildung 6: Detaillierte Übersicht der Nachverfolgungszeit des TC-Genotyp

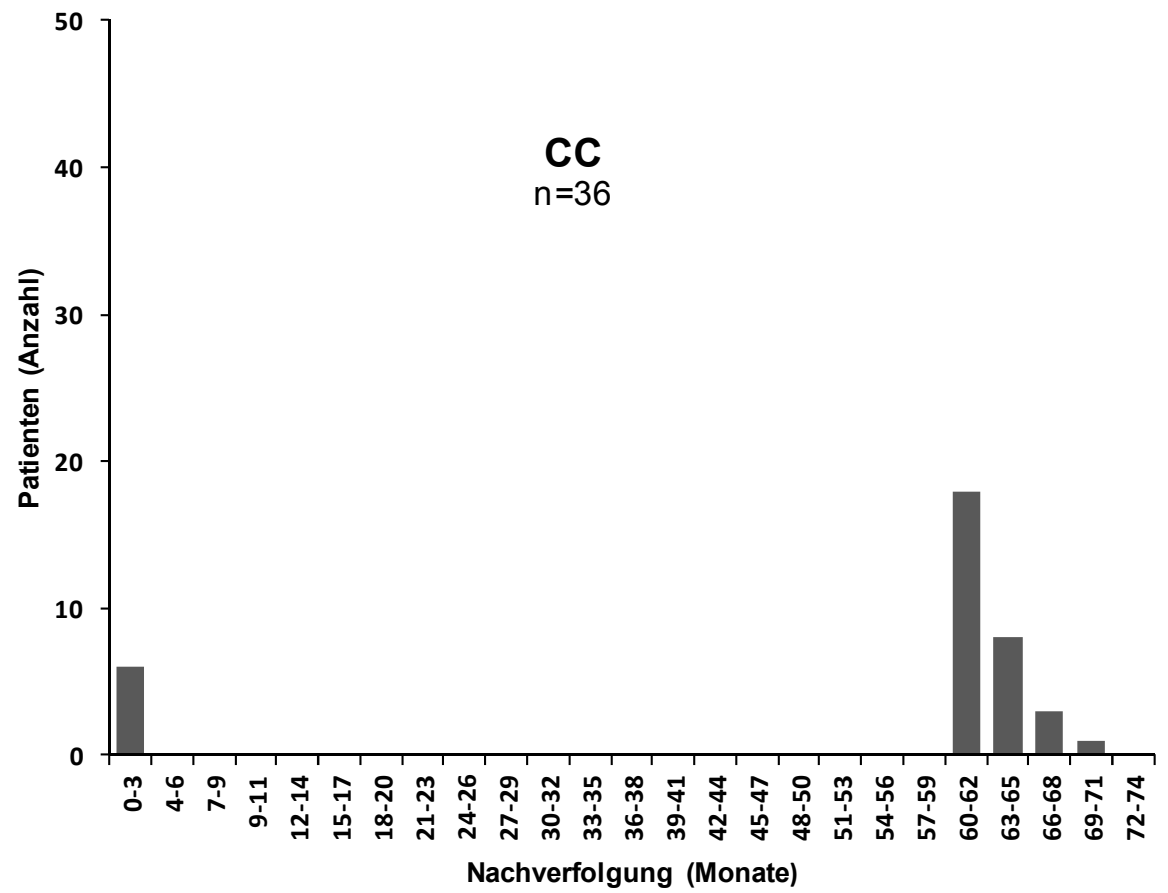

Abbildung 7: Detaillierte Übersicht der Nachverfolgungszeit des CC-Genotyp 


\subsection{Genotypen und Allelverteilung}

Nach Durchführung der Genanalyse wurden die Patienten entsprechend ihres Genotyps in drei Gruppen unterteilt: homozygote T-Allel Träger (TT = Wildtyp), homozygote C-Allel Träger (CC) und heterozygote Träger des C- und T-Allels. Die gesamte Genotypenverteilung unserer Studienpopulation des eNOS T-786C-Polymorphismus war TT $=208(42 \%), \mathrm{TC}=256(51 \%)$ und $\mathrm{CC}=36(7 \%)$. Die T- und C-Allel-Frequenz betrug 67\% und 33\%. Die Genotypenverteilung wurde anschließend mit einem ChiQuadrat-Test mit der erwarteten Verteilung innerhalb der normalen Bevölkerung laut dem Hardy-Weinberg-Gesetz berechnet. Die zu erwartende Genotypenverteilung wäre $\mathrm{TT}=226(45 \%), \mathrm{TC}=220(44 \%)$ und $\mathrm{CC}=54(11 \%)$ gewesen. Somit entsprach die Verteilung dieses Polymorphismus nach dem Chi-Quadrat-Test $(p-W e r t=0.0015)$ innerhalb der normalen Bevölkerung nicht dem Hardy-Weinberg-Gleichgewicht (HWG) (Henker 2011, Popov et al. 2010).

Tabelle 1: Genotypen- und Allelverteilung

\begin{tabular}{l|c|c|c}
\hline & $\begin{array}{c}\text { TT } \\
\mathrm{n}=208\end{array}$ & $\begin{array}{c}\text { TC } \\
\mathrm{n}=256\end{array}$ & $\begin{array}{c}\text { CC } \\
\mathrm{n}=36\end{array}$ \\
\hline \hline Genotypenverteilung (\%) & 42 & 51 & 7 \\
\hline
\end{tabular}

\begin{tabular}{c|c|c|c}
\hline & $\begin{array}{l}\text { T-Allel } \\
\mathrm{n}=672\end{array}$ & $\begin{array}{l}\text { C-Allel } \\
\mathrm{n}=328\end{array}$ & $\boldsymbol{p}$-Wert \\
\hline \hline Allelfrequenz (\%) & 67 & 33 & 0.0015 \\
\hline
\end{tabular}

(modifiziert, Henker 2011, Popov et al. 2010) 


\subsection{Prä- und intraoperative Daten}

Die Genotypenverteilung der drei Patientengruppen bezüglich des Altersdurchschnitts und der Geschlechtsverteilung war in allen drei Gruppen ähnlich und zeigte keinerlei Unterschiede. Die intraoperativ erhobenen Daten wie Operationszeitpunkt und Art des Eingriffs zeigten ebenfalls keine signifikanten Unterschiede und waren bei allen untersuchten Gruppen vergleichbar verteilt (Henker 2011, Popov et al. 2010).

Tabelle 2: Alters- und Geschlechtsverteilung

\begin{tabular}{c|c|c|c|c}
\hline & $\begin{array}{c}\text { TT } \\
\mathrm{n}=208\end{array}$ & $\begin{array}{c}\text { TC } \\
\mathrm{n}=256\end{array}$ & $\begin{array}{c}\text { CC } \\
\mathrm{n}=36\end{array}$ & $\boldsymbol{p}$-Wert \\
\hline \hline Alter (Jahre) & $66,7 \pm 10,9$ & $67,9 \pm 10,5$ & $68,0 \pm 8,7$ & 0,90 \\
\hline Geschlecht m (\%) & 68 & 61 & 69 & 0,28 \\
\hline
\end{tabular}

(modifiziert, Henker 2011, Popov et al. 2010) 
Tabelle 3: Operationszeitpunkt und Art der Eingriffe

\begin{tabular}{l|c|c|c|c}
\hline & $\begin{array}{c}\text { TT } \\
\mathrm{n}=208\end{array}$ & $\begin{array}{c}\text { TC } \\
\mathrm{n}=256\end{array}$ & $\begin{array}{c}\text { CC } \\
\mathrm{n}=36\end{array}$ & $\boldsymbol{p}$-Wert \\
\hline Operationszeitpunkt & & & & \\
Elektiv $\mathrm{n}=396(\%)$ & 78 & 79 & 86 & 0,9 \\
Dringlich $\mathrm{n}=41(\%)$ & 8 & 9 & 6 & 0,8 \\
Notfall $\mathrm{n}=63(\%)$ & 14 & 12 & 8 & 0,6 \\
Eingriffe & & & & \\
Bypass-OP $\mathrm{n}=251(\%)$ & & & & \\
Klappen-OP $\mathrm{n}=107(\%)$ & 52 & 48 & 53 & 0,72 \\
Kombinierter Eingriff $\mathrm{n}=101(\%)$ & 18 & 21 & 22 & 0,61 \\
Andere Eingriffe $\mathrm{n}=41(\%)$ & 9 & 9 & 3 & 0,31 \\
\hline
\end{tabular}

(modifiziert, Henker 2011, Popov et al. 2010)

\subsection{Morbidität im Langzeitverlauf}

Bezüglich der Morbidität im Langzeitverlauf konnten nur unzureichende Daten gewonnen werden, so dass keine klinisch relevanten Aussagen gemacht werden konnten. Dies lag an mehreren Faktoren. Zum einen gibt die erweiterte Melderegisterauskunft nur Daten bezüglich des Sterbedatums und -orts an und Daten zu der Morbidität werden dort nicht festgehalten. Zum anderen bestimmten die Hausärzte nur die Werte bzw. führten nur die Untersuchungen durch, die von klinischer Relevanz für den Patienten sind. Somit wurden Werte bzw. Untersuchungen, die in unserem Fragebogen erfragt wurden, teilweise gar nicht bzw. unregelmäßig durchgeführt und somit sind sie nicht verwertbar für klinische Beobachtungen. Zusätzlich wurden 29 Fragebögen durch direkten telefonischen Kontakt mit dem Patienten bearbeitet, hierbei konnten spezifische Werte wie aktuelle Laborwerte oder Werte zur Echokardiographie nicht eruiert werden. 


\subsection{Mortalität im Langzeitverlauf}

In Bezug auf die Todesursache verhielt es sich ähnlich wie bei der Morbidität. So konnte zwar in 39 Fällen eine Ursache (zwölf Fälle mit kardialen Ursachen, zehn Fälle mit Multiorganversagen bei Sepsis, acht Fälle mit Apoplex oder Hirnblutung, vier Fälle mit neu aufgetretenen Malignomen und fünf sonstige Todesursachen) als Todesgrund detektiert werden, jedoch bildete die Gruppe mit den unbekannten Todesgründen $(n=86)$ den Großteil. Dies lag, wie auch im Bereich der Morbidität, an mehreren Faktoren. Zum einen gibt die erweiterte Melderegisterauskunft nur Daten bezüglich des Sterbedatums und -orts an, Daten zu der Todesursache werden jedoch dort nicht festgehalten. Zum anderen führten die Kollegen, die an der initialen Studie beteiligt waren, keine Differenzierung der Todesursachen durch. Eine nachträglich von uns durchgeführte Analyse dieser verstorbenen Patienten, scheiterte jedoch aufgrund der bei den meisten Patienten aufgetretenen protrahierten Verläufe auf den Intensivstationen und der daraus resultierenden oftmals unmöglichen genauen Abgrenzbarkeit der Todesursache zwischen postoperativen Herz-Kreislauf-Versagen, Nierenversagen und postoperativ aufgetretener Sepsis mit anschließendem Multiorganversagen. Somit wurde bei Patienten wo eine Abgrenzbarkeit unmöglich war, um eine Verfälschung der Daten zu verhindern, die Todesursache als unbekannt eingestuft. Patienten bei denen eine klare Todesursache vorlag, wurden dementsprechend in die Liste der Todesursachen aufgenommen. Aufgrund dieser Datenlage konnten ebenfalls keine eindeutigen Aussagen bezüglich der klinischen Relevanz des Polymorphismus und den Ursachen, die zum Tode führten, gemacht werden. 
Tabelle 4: Todesursachen

\begin{tabular}{l|c|c}
\hline \multicolumn{1}{c|}{ Todesursachen } & Gesamtmortalität $\mathrm{n}=125$ & Anteil in \% \\
\hline \hline Kardiale Ursachen & 12 & 10 \\
Multiorganversagen bei Sepsis & 10 & 8 \\
Neurologische Ursachen & 8 & 6 \\
Malignome & 4 & 3 \\
Sonstige & 5 & 4 \\
Unbekannt & 86 & 69 \\
\hline
\end{tabular}

Die Analyse der Sterblichkeit zeigte in der Vorgängerstudie eine direkte peri/postoperative Mortalität von 8,2\% $(\mathrm{n}=41)$ (Henker 2011, Popov et al. 2010). Hinzu kamen in der aktuellen Datenerhebung innerhalb des von uns betrachteten Nachbeobachtungszeitraums (Out-of-Hospital-Mortalität) weitere 16,8\% $(n=84)$ dazu. Somit ergab sich eine Gesamtmortalität (5-Jahres-Mortalität) von 25\% ( $n=125)$ für das Gesamtkollektiv von 500 Patienten nach Ablauf von fünf Jahren. Eine erhöhte Sterblichkeit spezifischer Allelträger konnte in der initialen Studie nicht eruiert werden $(\mathrm{p}=0.15)$, jedoch zeigte die Subgruppen-Analyse eine deutlich erhöhte Mortalität $(\mathrm{p}=0.01)$ der homozygoten C-Allelträger, die einer Notfalloperation unterzogen werden mussten. Bei elektiven und dringlichen Operationen gab es keinen signifikanten Unterschied bezogen auf die Genotypen (Henker 2011, Popov et al. 2010). Nach einem Nachbeobachtungszeitraum von fünf Jahren zeigten sich hinsichtlich der Gesamtmortalität sowie der Out-of Hospital-Mortalität, bezogen auf die einzelnen 
Genotypen, jedoch keine signifikanten Unterschiede. Die Subgruppen-Analyse zeigte zwar weiterhin in der Gruppe der CC-Allelträger, die sich Notfalloperationen unterziehen mussten, eine Korrelation, jedoch waren die hier erhobenen Daten identisch zu der Vorgängerstudie und es kamen keine neuen Todesfälle hinzu. Wie bereits in der Zielsetzung beschrieben, wies zudem die Subgruppe eine relativ geringe Fallzahl auf. Somit wies kein Genotyp dieser Genvariante eine signifikant erhöhte Mortalität hinsichtlich der untersuchten Zeitpunkte (peri-/postoperativ, Out-of-Hospital, 5-JahresMortalität) auf.

Tabelle 5: Peri-/postoperative Mortalität mit Subgruppen-Analyse

\begin{tabular}{l|c|c|c|c}
\hline \multicolumn{1}{c|}{ Mortalität } & $\begin{array}{c}\text { TT } \\
\mathrm{n}=208\end{array}$ & $\begin{array}{c}\text { TC } \\
\mathrm{n}=256\end{array}$ & $\begin{array}{c}\text { CC } \\
\mathrm{n}=36\end{array}$ & $\boldsymbol{p}$-Wert \\
\hline \hline Peri-/postoperative Mortalität $\mathrm{n}=41(\%)$ & 7 & 8 & 17 & 0.15 \\
Elektiv-OP $\mathrm{n}=26(\%)$ & 5 & 7 & 13 & 0.25 \\
Dringliche OP $\mathrm{n}=6$ (\%) & 12 & 18 & 0 & 0.71 \\
Notfall-OP $\mathrm{n}=9$ (\%) & 17 & 6 & 67 & 0.01 \\
\hline
\end{tabular}

(modifiziert, Henker 2011, Popov et al. 2010) 
Tabelle 6: 5-Jahres-Mortalität mit Subgruppen-Analyse

\begin{tabular}{l|c|c|c|c}
\hline \multicolumn{1}{c|}{ Mortalität } & $\begin{array}{c}\text { TT } \\
\mathrm{n}=208\end{array}$ & $\begin{array}{c}\text { TC } \\
\mathrm{n}=256\end{array}$ & $\begin{array}{c}\text { CC } \\
\mathrm{n}=36\end{array}$ & $\boldsymbol{p}$-Wert \\
\hline \hline 5-Jahres-Mortalität $\mathrm{n}=125$ (\%) & 24 & 25 & 36 & $\mathrm{~ns}$ \\
Elektiv-OP $\mathrm{n}=98$ (\%) & 24 & 25 & 32 & $\begin{array}{l}\text { TT vs TC/CC }=0.35 \\
\text { TC vs TT/CC }=0.52 \\
\text { CC vs TT/TC }=0.21\end{array}$ \\
Dringliche OP $\mathrm{n=16( \% )}$ & 35 & 41 & 50 & $\begin{array}{l}\text { TT vs TC/CC }=0.46 \\
\text { TC vs TT/CC }=0.52 \\
\text { CC vs TT/TC }=0.63\end{array}$ \\
\hline Notfall-OP $\mathrm{n}=11$ (\%) & 17 & 13 & 67 & $\begin{array}{l}\text { TT vs TC/CC }=0.61 \\
\text { TC vs TT/CC }=0.27 \\
\text { CC vs TT/TC }=0.07\end{array}$ \\
\hline
\end{tabular}

ns $=$ nicht signifikant 
Tabelle 7: Mortalitätsraten im Vergleich

\begin{tabular}{c|c|c|c|c}
\hline \multicolumn{1}{c|}{ Mortalität } & $\begin{array}{c}\text { TT } \\
\mathrm{n}=208\end{array}$ & $\begin{array}{c}\text { TC } \\
\mathrm{n}=256\end{array}$ & $\begin{array}{c}\text { CC } \\
\mathrm{n}=36\end{array}$ & -Wert \\
\hline \hline Peri-/postoperativ $\mathrm{n}=41(\%)$ & 7 & 8 & 17 & $\mathrm{~ns}$ \\
Out-of-Hospital $\mathrm{n}=84(\%)$ & 16 & 17 & 19 & $\mathrm{~ns}$ \\
5-Jahres-Mortalität $\mathrm{n}=125(\%)$ & 24 & 25 & 36 & $\mathrm{~ns}$ \\
\hline
\end{tabular}

ns $=$ nicht signifikant

Hinsichtlich des Todesalters (in Jahren) und des Alters bei Studien-Einschluss konnten ebenfalls keine signifikanten Unterschiede festgestellt werden und die Verteilung wies bei allen untersuchten Gruppen vergleichbare Werte auf.

Tabelle 8: Überlebensdauer, Alter bei Studien-Einschluss und Tod

\begin{tabular}{l|c|c|c|c}
\hline & $\begin{array}{c}\text { TT } \\
\mathrm{n}=49\end{array}$ & $\begin{array}{c}\text { TC } \\
\mathrm{n}=63\end{array}$ & $\begin{array}{c}\text { CC } \\
\mathrm{n}=13\end{array}$ & p-Wert \\
\hline \hline Alter bei Einschluss (Jahre) & $73 \pm 7$ & $71 \pm 7$ & $72 \pm 7$ & $\mathrm{~ns}$ \\
Gelebte Tage nach OP & $565 \pm 523$ & $508 \pm 550$ & $298 \pm 505$ & $\mathrm{~ns}$ \\
Alter bei Tod (Jahre) & $75 \pm 7$ & $73 \pm 7$ & $73 \pm 7$ & $\mathrm{~ns}$ \\
\hline
\end{tabular}

ns = nicht signifikant 
In Bezug auf die Langzeitmortalität zeigten homozygote C-Allelträger im Langzeitverlauf eine erniedrigte Überlebenszeit (gelebte Tage nach Operation) mit 298 \pm 505 gegenüber $565 \pm 523$ (TT-Allelträger) und $508 \pm 550$ (TC-Allelträger) Tagen, jedoch ohne statistische Signifikanz. Mittels der Kaplan-Meier-Kurve wurden die Überlebensraten der drei Genotypen bestimmt. Hierzu wurden zu jedem Jahr direkt die kumulativen Prozentsätze von verstorbenen Patienten aufgetragen. Dabei konnte jedoch kein Genotyp identifiziert werden, welcher eine statistisch signifikante bessere oder schlechtere Überlebenszeit im Langzeitverlauf aufwies (Log-rank-Test $\mathrm{p}=0,09)$.

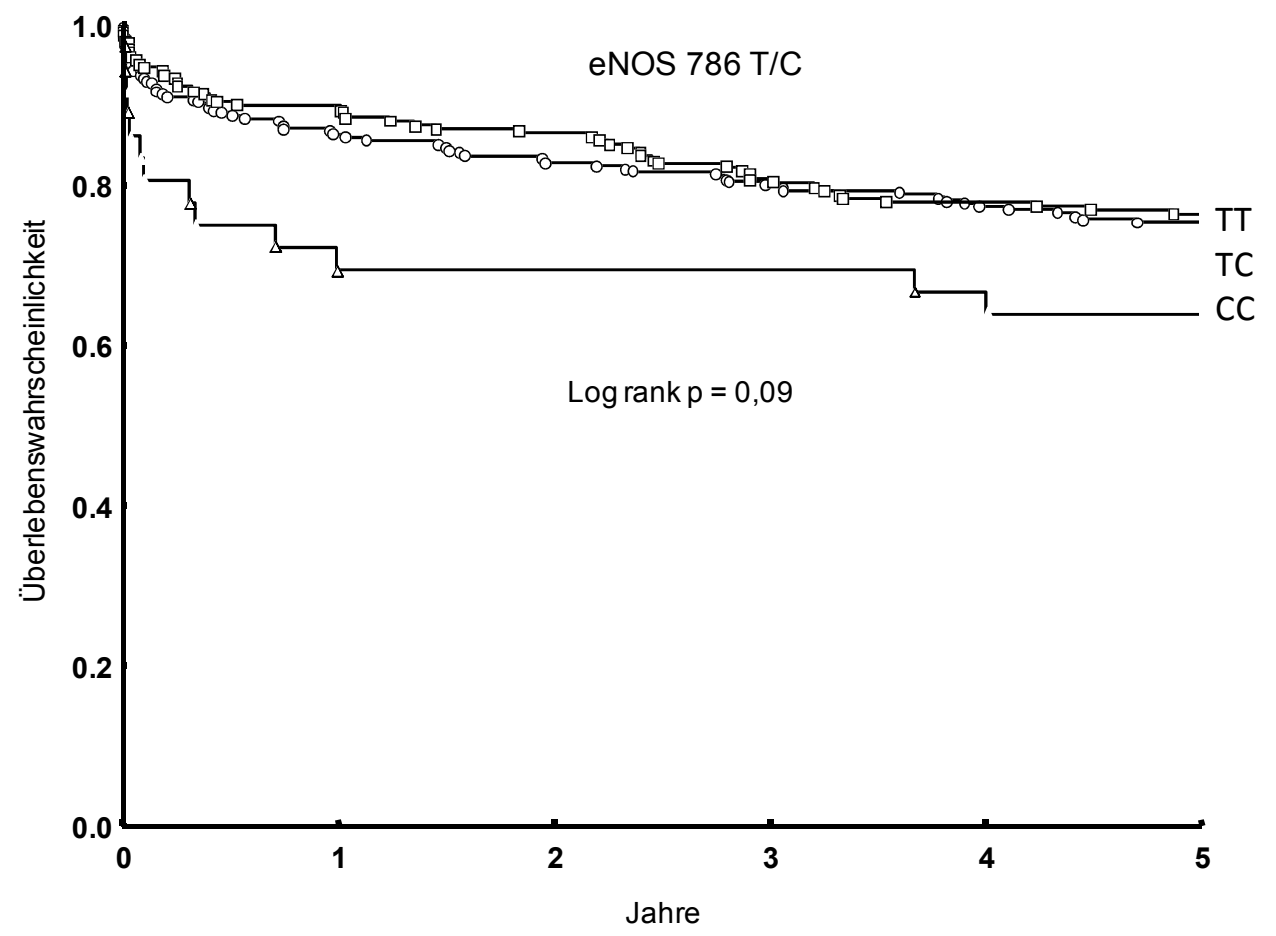

Abbildung 8: Langzeitüberlebensraten der Patienten anhand ihres Genotyps (Log-rank-Test $\mathrm{p}=0,09)$ 


\section{Diskussion}

Ziel der Studie war es, den klinischen Einfluss des T-786C-Polymorphismus auf die Mortalität und Morbidität im 5-Jahresverlauf von Patienten nach herzchirurgischen Eingriffen mit einer extrakorporalen Zirkulation zu untersuchen. Dabei stützt sich die hier durchgeführte Arbeit auf die Ergebnisse von Popov und Kollegen (Henker 2011, Popov et al. 2010), wonach ein signifikanter Zusammenhang zwischen homozygoten Trägern des C-Allels und der peri-/postoperativen Sterblichkeit nach herzchirurgischen Operationen mit einer extrakorporalen Zirkulation nachgewiesen werden konnte. Basis war dabei eine zum damaligen Zeitpunkt bereits nachgewiesene Assoziation des Polymorphismus auf die Entwicklung bestimmter Formen der ischämischen Herzkrankheit und anderer Herz-Kreislauf-Erkrankungen sowie eine deutlich veränderte NO-Bioverfügbarkeit und -Synthese bei herzchirurgischen Eingriffen mit Verwendung einer extrakorporalen Zirkulation. Angesicht dieser Tatsache und der fehlenden Daten in diesem Bereich war das damalige Studienziel $\mathrm{zu}$ untersuchen, inwieweit der T-786C-Polymorphismus den direkten peri-/postoperativen Verlauf solcher Patienten beeinflussen könnte, um eventuell als ein eigenständiger Risikofaktor für eine erhöhte Mortalität nach herzchirurgischen Eingriffen zu gelten. Der Nachweis gelang in einer Subgruppe von homozygoten C-Allelträgern, wenn diese sich Notfalloperationen unterziehen mussten, die anderen Subgruppen zeigten hinsichtlich der Mortalität jedoch keine signifikanten Unterschiede bezogen auf die Genotypen (Henker 2011, Popov et al. 2010). Da herzchirurgische Patienten ohnehin eine erhöhte Mortalität nach Notfalloperationen aufweisen (Sergeant et al. 2003), die Subgruppe eine relativ geringe Fallzahl aufwies und der Polymorphismus zu einer dauerhaften Verringerung der eNOS-Aktivität und daraus resultierender Verminderung der NO-Produktion beiträgt, könnte es eine deutlichere Assoziation in den Subgruppen im Langzeitverlauf geben (z.B. erhöhte Bypassverschlussrate mit daraus folgender erhöhter Mortalität). Das Hauptaugenmerk lag in dieser Studie ebenfalls bei den homozygoten C-Allelträgern, da diese in der früheren Studie eine leichte Assoziation aufzeigen konnten. Nach einem Nachbeobachtungszeitraum von fünf Jahren zeigten sich in diesem Patientenkollektiv, welches nachuntersucht wurde, hinsichtlich der Mortalität bezogen auf die einzelnen 
Genotypen jedoch keine signifikanten Unterschiede. Somit kann der T-786C-Polymorphismus nicht als Risikofaktor nach herzchirurgischen Eingriffen mit einer extrakorporalen Zirkulation fungieren.

Wie bereits eingangs erwähnt, stellen Krankheiten des Herz-Kreislauf-Systems die häufigste Todesursache innerhalb der westlichen Industrienationen dar. Zusätzlich verursachen sie einen immensen Kostenaufwand im Gesundheitssystem. Die molekularbiologische Grundlagenforschung in diesem Bereich hat unser Verständnis bezüglich der physiologischen Abläufe sowie die pathophysiologischen Mechanismen, die zu diesen Erkrankungen führen, in den letzten Jahren deutlich verändert und damit die Medizin revolutioniert. So konnten einige genetische Faktoren, die zu der Entstehung dieser komplexen Erkrankungen führen, identifiziert werden. Da Herz-Kreislauf-Erkrankungen aus der Summe von exogenen und genetischen Faktoren entstehen, sind vor allem genetische Veränderungen bzw. Variabilitäten interessant, die einen Einfluss auf die Erkrankung und deren Ausprägung anhand klinischer Parameter zeigen (Hingorani 2001). Eine solche genetische Variabilität stellt der von uns untersuchte Polymorphismus dar, der mit einer Reduktion der Promotoraktivität (von 40-50\%) und damit der Transkription einhergeht. Dadurch kommt es zu einer quantitativen Abnahme der entstehenden eNOS mit daraus resultierender Verminderung des gebildeten NO. So konnten bereits einige Genassoziationsstudien den Zusammenhang zwischen dem eNOS T-786C-Polymorphismus und Myokardinfarkten, der KHK und Koronarspasmen aufzeigen (Dosenko et al. 2006, Hingorani 2001, Rossi et al. 2003). Obwohl herzchirurgische Eingriffe mit extrakorporaler Zirkulation zu deutlichen Veränderungen der NO-Bioverfügbarkeit und -Synthese führen und bei diesen Patienten eine gemeinsame Endstrecke zwischen der polymorphismusassoziierten Atherosklerose und der sklerotischen KHK und Klappenvitien der Patienten besteht, sind solche Genassoziationsstudien bzw. klinisch relevanten Studien im Bereich der Herzchirurgie im Gegensatz zu den konservativen Fächern jedoch selten. Ursachen für die wenigen Studien sind auf der einen Seite die geringere Anzahl an behandelten Patienten in den operativen Fächern und auf der anderen Seite die benötigten hohen Fallzahlen für solche Studien, um aussagekräftige Ergebnisse nachweisen zu können. 
Die in unserer Studie eingeschlossenen 500 Patienten zeigten, nach einer vor Studienbeginn durchgeführten Poweranalyse, eine ausreichende Größe der Studienpopulation, um genetische Effekte bei den einzelnen Genotypen hinsichtlich der Mortalität und Morbidität nachweisen und aussagekräftige Ergebnisse liefern zu können. Die Studie stellt eine der größten Genassoziationsstudien im Bereich der Herzchirurgie hinsichtlich der eNOS und postoperativer Morbidität, Mortalität und der eingeschlossenen Patienten im Langzeitverlauf in Europa dar. Die Geschlechter- und Altersverteilung zeigte keine Unterschiede innerhalb der drei Allelgruppen. Auch die durchgeführten operativen Eingriffe und die Operationszeitpunkte waren zwischen den Gruppen ähnlich verteilt. Die Genotypenverteilung der Studienpopulation entsprach nicht dem Hardy-Weinberg-Gleichgewicht, d.h. der zu erwarteten Verteilung in der Bevölkerung. Das Hardy-Weinberg-Gleichgewicht sagt aus, dass die relative Häufigkeit, mit der bestimmte Allele im Genpool (Summe aller Gene einer Art) vertreten sind, bei einer idealen Population über Generationen konstant bleibt. Dabei müssen die Eigenschaften einer idealen Population (keine Mutation, unendlich große Population, Panmixie, keine Selektion und keine Migration) erfüllt sein (Hardy 1908). In unserer Studienpopulation muss jedoch von einer gewissen Vorselektion ausgegangen werden, da die meisten Patienten aus dem Gebiet Mittel- und Südniedersachsen stammen. Dies spiegelt geographisch gesehen nur einen geringen Anteil aller Patienten wider, die sich herzchirurgischen Operationen in der Bundesrepublik Deutschland unterziehen müssen. So kann es sein, dass die Genotypenverteilung in Südniedersachsen nicht genau der in der Gesamtbevölkerung entspricht. Es handelt sich bei dem Patientenkollektiv um kardial vorerkrankte Patienten, die alle eine herzchirurgische Operation benötigten, was ebenfalls eine Vorselektion beinhaltet. Ein Vergleich mit gesunden Probanden bzw. mit Patienten, die einer Intervention bedürften, wurde nicht durchgeführt. Es wäre demnach denkbar, dass eine erhöhte Anzahl an C-Allelträgern in dieser Studie vorlag als es in der Normalbevölkerung der Fall ist. Außerdem zeigt das Patientenkollektiv hinsichtlich der homozygoten C-Allelträger eine weitere Einschränkung der Studie auf. Da das C-Allel als prädisponierender Faktor für die Entstehung der kardiovaskulären Erkrankungen angesehen wird, war die Anzahl der homozygoten C-Allelträger mit $n=36$ jedoch gering, so dass die nicht statistisch signifikanten Ergebnisse eventuell an der zu kleinen 
Gruppe liegen könnten. Der Einschluss der Patienten in die Studie erfolgte zufällig, wodurch die Voraussetzung, wie das Fehlen von Migration ebenfalls nicht gegeben war. Das Abweichen, von dem theoretischen Model des Hardy-Weinberg-Gleichgewicht, könnte eventuell eine Einschränkung bezüglich der Aussagekraft dieser Studie bedeuten.

Perioperative Komplikationen können die Morbidität und Mortalität chirurgischer Patienten beeinflussen und führen meistens $\mathrm{zu}$ einem verlängertem Intensiv- und Krankenhausaufenthalt. Zu den wichtigsten Komplikationen in der Herzchirurgie zählen die postoperative Blutung, Herzrhythmusstörungen, Wundinfektionen, der Myokardinfarkt und der Schlaganfall. Diese Komplikationen können sogar zu einem postoperativen Organversagen führen, was mit einer deutlich erhöhten Mortalität der behandelten Patienten verbunden ist. Seit langem ist bekannt, dass bestimmte Erbkrankheiten $\mathrm{zu}$ einem veränderten perioperativen Risiko chirurgischer Patienten führen können. Zusätzlich zeigten einige Studien in den letzten Jahren, dass auch spezifische Genotypen von Individuen mit einer schlechten Prognose bei ansonsten gesunden Individuen einhergehen können. Die Identifikation dieser Genotypen konnte unser Verständnis hinsichtlich der variierenden physiologischen Reaktionen der Individuen auf chirurgische Maßnahmen verbessern. Zusätzlich können solche spezifischen Genotypen als präoperative genetische Marker für die Risikoadjustierung chirurgischer Patienten dienen und damit die postoperative Morbidität und Mortalität, durch Anpassung therapeutischer Maßnahmen, senken (Ziegeler et al. 2003). Außerdem können sie die Prognosefähigkeit der traditionellen Mortalitäts-Vorhersagemodelle, wie den in der Herzchirurgie verwendeten EuroSCORE II (European System for Cardiac Operative Risk Evaluation) (Nashef et al. 2012), verbessern, da in den meisten Vorhersagemodellen keine genetischen Risikofaktoren enthalten sind (Lobato et al. 2011).

Trotz der geringen Anzahl an Genassoziationsstudien im herzchirurgischen Bereich konnten jedoch die wenigen durchgeführten Studien interessante Ergebnisse hinsichtlich solcher spezifischer Genotypen detektieren. So zeigte z.B. das PEGASUSTeam (Perioperative Genetics and Safety Outcome Study Investigative Team) einen Zusammenhang zwischen bestimmten Polymorphismen und dem vermehrten Auftreten 
von postoperativem Myokardinfarkt (Podgoreanu et al. 2006), Schlaganfall (Grocott et al. 2005), Nierenversagen (Stafford-Smith et al. 2005), neurologischem Defizit (Mathew et al. 2007) und postoperativer Blutungsneigung (Welsby et al. 2005). Dieses Forschungsteam untersucht an einem der größten Patientenkollektive viele verschiedene Genpolymorphismen hinsichtlich unterschiedlicher klinischer Endpunkte, um ebenfalls eine Risikoabschätzung herzchirurgischer Patienten $\mathrm{zu}$ ermöglichen. Neben dem PEGASUS-Team konnten aber auch andere Forschungsgruppen eine Assoziation solcher Genpolymorphismen bzw. spezifischer Genotypen mit einer erhöhten Inflammation (Tomasdottir et al. 2003) und dem vermehrten Auftreten von postoperativem Vorhofflimmern bei herzchirurgischen Patienten aufzeigen (Gaudino et al. 2003). Ebenfalls zwei wichtige klinische Endpunkte, die die Morbidität der behandelten Patienten erhöhen können.

Da für die eNOS bereits mehrere Genpolymorphismen bekannt sind, die in den konservativen Fächern eine positive Assoziation mit Herz-Kreislauf-Erkrankungen aufzeigten und herzchirurgische Eingriffe mit Verwendung einer extrakorporalen Zirkulation $\mathrm{zu}$ deutlichen Veränderungen der NO-Bioverfügbarkeit und -Synthese führen, wurden diese ebenfalls in Genassoziationsstudien hinsichtlich einer erhöhten Morbidität und Mortalität untersucht. So konnte eine Assoziation des G-894T-Polymorphismus mit einer erhöhten Inzidenz für kongenitale Herzfehler bei homozygoten T-Allelträgern nachgewiesen werden (van Beynum et al. 2008). Zusätzlich zeigten weitere Studien einen Zusammenhang zwischen diesem Polymorphismus und erhöhter postoperativer Niereninsuffizienz im Zusammenspiel mit anderen Genpolymorphismen (Stafford-Smith et al. 2005) und eine veränderte vaskuläre Reaktivität auf $\alpha$-adrenerge Stimulation (Philip et al. 1999).

Studien hinsichtlich des von uns untersuchten T-786C-Polymorphismus zeigten jedoch kontroverse Ergebnisse bezüglich der Morbidität herzchirurgischer Patienten. So konnten Popov und Kollegen den T-786C-Polymorphismus als einen Risikofaktor für die Entwicklung eines postoperativen Nierenversagens und den Einsatz einer Nierenersatztherapie bei herzchirurgischen Patienten detektieren. Hier waren die C-Allelträger häufiger betroffen und zeigten zusätzlich eine signifikante Reduktion der Kreatinin-Clearance und eine niedrigere Kreatinin-Clearance (Popov et al. 2009). Im Gegensatz dazu zeigte eine Studie von Liakopoulos und Kollegen keine Assoziation 
zwischen postoperativ aufgetretenen hämodynamischen Veränderungen und Organfunktionsstörungen bei herzchirurgischen Patienten. Jedoch war hier das Patientenkollektiv deutlich geringer und der Beobachtungszeitraum betrug nur 24 Stunden (Liakopoulos et al. 2006).

Basierend auf diesen kontroversen Ergebnissen und den fehlenden Daten im Langzeitverlauf wurde im Rahmen der vorliegenden Studie versucht festzustellen, welchen klinischen Einfluss der T-786C-Polymorphimus auf die Langzeitmorbidität herzchirurgischer Patienten nach Eingriffen mit einer extrakorporalen Zirkulation hat. Die Annahme war, dass es eine deutlichere Assoziation hinsichtlich der Organfunktionsstörungen in den einzelnen Subgruppen im Langzeitverlauf geben könnte, da der Polymorphismus zu einer dauerhaften Verringerung der eNOS-Aktivität beiträgt. Besonderes Augenmerk wurde hierbei auf Funktionsstörungen bzw. neu aufgetretene Erkrankungen im Bereich des Herzen, der Niere und des ZNS gelegt, da hier bereits eine positive Assoziation mit dem Polymorphismus in den konservativen Fächern beschrieben wurde.

So konnten bereits mehrere Studien die Assoziation zwischen dem von uns untersuchten Polymorphismus und einem ischämischen Schlaganfall auf dem Boden einer Karotisstenose nachweisen. Demnach gilt das homozygote C-Allel als unabhängiger Risikofaktor für die Entstehung einer mittleren bis schweren Arteria carotis interna Stenose (Ghilardi et al. 2002). Zusätzlich zeigten homozygote C-Allelträger eine erhöhte Anfälligkeit für zerebrale Aneurysmarupturen und die Gefahr des Vasospasmus nach diesen (Ko et al. 2008). Da der zerebrale Vasospasmus eine gefürchtete Komplikation darstellt, kann er ebenfalls zu einer erhöhten Morbidität und Mortalität der Patienten beitragen.

Neben der Assoziation des T-786C-Polymorphismus mit dem vermehrten Auftreten von Myokardinfarkten, Koronarspasmen und der koronaren Herzerkrankung, konnten auch klinische Studien hinsichtlich koronarer Stentimplantation positive Ergebnisse liefern. Demnach ist die In-Stent-Restenose sowie das Risiko einen Myokardinfarkt $\mathrm{zu}$ erleiden und das Versterben nach Stentimplantation bei homozygoten C-Allelträgern deutlich höher als die der anderen Genotypen (Gomma et al. 2002). Zudem konnten auch Studien eine komplette Insensitivität gegenüber dem shear stress bei C-Allelträgern nachweisen. Bei diesem Genotyp kommt es ebenfalls zu 
einer abgeschwächten physiologischen Antwort auf die Hypoxie als Transkriptionsreiz, dies führt zu einer inadäquaten Antwort des Endothels auf diesen Reiz (Rossi et al. 2003). Da neben den direkten Auswirkungen des T-786C-Polymorphismus auf das eNOS-Gen auch die Aktivierungswege, die zu der Erhöhung der NO-Produktion führen, ebenfalls negativ durch diesen beeinflusst werden, könnte dies bei herzchirurgischen Patienten eventuell $\mathrm{zu}$ einer erhöhten Bypassverschlussrate führen und damit $\mathrm{zu}$ erhöhten Interventionsraten bzw. Re-Operationen, wodurch sich ebenfalls die Morbidität im Langzeitverlauf erhöhen würde. So wurde in der vorgelegten Arbeit versucht, solche Morbiditäten aufzudecken, die im Zusammenhang mit einem spezifischen Genotyp des Polymorphismus stehen.

Nach einem Nachbeobachtungszeitraum von fünf Jahren ließen sich hinsichtlich der Genotypen keine signifikant gehäuften Morbiditäten in den untersuchten Organsystemen nachweisen. Jedoch müssen die gewonnen Daten als nicht aussagekräftig gewertet werden, da nur 329 der 459 versandten Fragebögen zurückgesendet wurden und diese teilweise nicht vollständig genug ausgefüllt waren. Zusätzlich ermöglichten die anderen angewandten Methoden hinsichtlich der Morbidität keine Datenerhebung. Somit konnten bezüglich der Morbidität im Langzeitverlauf nur unzureichende Daten gewonnen werden, so dass keine klinisch relevanten Aussagen gemacht werden können.

Die unzureichende Gewinnung von Daten bezüglich der Morbidität zeigte einen Schwachpunkt der Studie hinsichtlich der ausgewählten Methoden zur Datenerhebung auf. Dies lag an mehreren Faktoren. Zum einen gibt die erweiterte Melderegisterauskunft nur Daten bezüglich des Sterbedatums und -orts an, Daten zu der Morbidität werden dort nicht festgehalten. Zum anderen bestimmen die Hausärzte nur die Werte bzw. führen nur die Untersuchungen durch, die von klinischer Relevanz für den Patienten sind. Somit wurden Werte bzw. Untersuchungen die in unserem Fragebogen erfragt wurden teilweise gar nicht bzw. unregelmäßig durchgeführt und somit sind sie für klinische Beobachtungen nicht verwertbar. Eine bessere Möglichkeit zur Datengewinnung stellt die regelmäßige Kontrolle solcher Patienten in definierten Zeitabständen in den Einrichtungen, in denen solche Studien durchgeführt werden, dar. Somit können vollständige Daten gewonnen werden, die klinische Aussagen ermöglichen. 
Da die spezifischen Genotypen neben der Morbidität auch die Mortalität beeinflussen können, wurden klinische Studien hinsichtlich der Assoziation solcher Genpolymorphismen mit einer erhöhten postoperativen Mortalität ebenfalls durchgeführt. So konnte in einer Studie des PEGASUS-Teams eine Assoziation zwischen den Varianten des Thrombomodulin-Gens und einer erhöhten Mortalitätsrate bei Pateinten nach koronarer Bypassoperation nachgewiesen werden (Lobato et al. 2011). Die Genvarianten der eNOS wurden ebenfalls hinsichtlich einer solchen Assoziation untersucht. So konnten Popov und Kollegen einen Zusammenhang zwischen dem T-786C-Polymorphimus und einer direkt peri-/postoperativ erhöhten Mortalität in einer Subgruppe von herzchirurgischen Patienten aufzeigen. Hierbei waren homozygote C-Allelträger, wenn sie sich einer Notfalloperation unterziehen mussten, mit einer deutlich höheren Mortalität behaftet als TT- oder TC-Allelträger. Bei elektiven und dringlichen Operationen gab es keinen signifikanten Unterschied bezogen auf die Genotypen. Auch hinsichtlich der durchgeführten Eingriffe ließen sich keine Unterschiede in den Subgruppen feststellen (Henker 2011, Popov et al. 2010).

Aufbauend auf diesen Ergebnissen, die eine erhöhte Sterblichkeitsrate bei homozygoten C-Allelträgern bei Notfalloperationen detektieren konnten, wurde in der von uns durchgeführten Studie versucht, Langzeitergebnisse hinsichtlich der Mortalität zu gewinnen. Da herzchirurgische Patienten ohnehin eine erhöhte Mortalität nach Notfalloperationen aufweisen (Sergeant et al. 2003), die Subgruppe eine relativ geringe Fallzahl aufwies und der Polymorphismus zu einer dauerhaften Verringerung der eNOS-Aktivität und daraus resultierender Verminderung der NO-Produktion beiträgt, war die Annahme, dass es eine deutlichere Assoziation in den Subgruppen im Langzeitverlauf geben (z.B. erhöhte Bypassverschlussrate mit daraus erhöhter Mortalität) könnte.

Nach Ablauf von fünf Jahres zeigte die Analyse der Sterblichkeit eine 5-JahresMortalität von 25\% für das Gesamtkollektiv von 500 Patienten. Trotz eines Datenrücklaufes von $100 \%$ in diesem Anteil der Studie, ließen sich in den einzelnen Subgruppen (elektive, dringliche, Notfalloperationen) keine signifikanten Unterschiede hinsichtlich der Mortalität bezogen auf die Genotypen feststellen. Auch hinsichtlich der unterschiedlichen Eingriffe (singuläre Bypassoperation, singuläre Klappenoperation, Kombinationseingriffe) waren keine Unterschiede bei den einzelnen Genotypen 
festzustellen. Zwar zeigten homozygote C-Allelträger im Langzeitverlauf eine erniedrigte Überlebenszeit, jedoch ohne statistische Signifikanz. Bezüglich des Todesalters konnten ebenfalls keine signifikanten Unterschiede festgestellt werden und die Verteilung wies bei allen untersuchten Gruppen vergleichbare Werte auf. Somit ließ sich kein Genotyp als möglicher Risikofaktor für eine erhöhte Langzeitmortalität detektieren, obwohl das C-Allel als Risikofaktor für kardiovaskuläre Erkrankungen angesehen wird. Demnach lässt sich sagen, dass der T-786C-Polymorphismus keinen klinischen Einfluss auf die Mortalität im Langzeitverlauf von Patienten nach herzchirurgischen Eingriffen mit einer extrakorporalen Zirkulation hat.

Die in unserer Studie festgestellte 5-Jahres-Mortalität von 25\% zeigt sich übereinstimmend mit Ergebnissen anderer Langzeitstudien hinsichtlich der Mortalität. So betrug z.B. in einer Studie von Shahian und Mitarbeitern die 3-Jahresmortalitätsrate 23,3\% (Shahian et al. 2012). Eine weitere Studie konnte eine Mortalitätsrate von 24,2\% nach Ablauf von sieben Jahren detektieren (Wu et al. 2012). Somit sind die Ergebnisse unserer Studie hinsichtlich der Gesamtmortalität im Langzeitverlauf mit anderen internationalen Studien vergleichbar und spiegeln die allgemeinen Sterblichkeitsraten herzchirurgischer Patienten wider.

In Bezug auf die Todesursache verhielt es sich ähnlich wie bei der Morbidität. So konnte zwar in 39 Fällen eine Ursache als Todesgrund ermittelt werden, jedoch bildete die Gruppe mit den unbekannten Todesgründen $(n=86)$ den Großteil. Somit ließen sich hinsichtlich kardiovaskulärer Ereignisse, die zum Tode führten, keine eindeutigen Ergebnisse ermitteln. Aufgrund dieser Datenlage konnten ebenfalls keine eindeutigen Aussagen bezüglich der klinischen Relevanz des Polymorphismus und den Ursachen die zum Tode führten gemacht werden.

Fazit ist, dass der T-786C-Polymorphimus nicht als prädiktiver Risikofaktor für eine erhöhte Mortalität im Langzeitverlauf bei Patienten nach herzchirurgischen Eingriffen mit Verwendung einer extrakorporalen Zirkulation angesehen werden kann. Eine Schwäche der Studie könnte hinsichtlich der Auswahl der durchgeführten Operationen sowie des Operationszeitpunktes sein, da sowohl elektive, dringliche als auch Notfalloperationen untersucht worden sind. Ebenso gilt dies für die durchgeführten Operationen, die singuläre Bypass- und Klappenoperationen sowie Kombinationsein- 
griffe und Eingriffe an den großen herznahen Gefäßen enthielten. So könnten weitere Studien, die nur Patienten mit einer koronaren Bypassoperation untersuchen oder nur elektive Eingriffe einschließen, vielleicht das Ergebnis bestätigen. 


\section{Zusammenfassung}

Kardiovaskuläre Erkrankungen gehen mit Veränderungen des Blutgefäßsystems wie z.B. der Arteriosklerose und Endotheldysfunktionen einher. Nach wie vor stellen Herz-Kreislauf-Erkrankungen die häufigste Todesursache innerhalb westlicher Industrienationen dar und verursachen zusätzlich immense Kosten in den Gesundheitssystemen der jeweiligen Länder. Dem Verständnis der Pathogenese dieser Erkrankungen kommt somit nicht nur hinsichtlich möglicher Therapieansätze eine wichtige Bedeutung zu, sondern auch aus Sicht der Prävention. Faktoren, die zu der Entwicklung atherosklerotischer Veränderung beitragen, sind polygenetisch und multifaktoriell. Neben habituellen, umweltbedingten und demographischen Einflussfaktoren spielen auch genetische Normvarianten eine wichtige Rolle. Diese genetischen Normvarianten bzw. Genpolymorphismen stellen hierbei eine nicht beeinflussbare Prädisposition der Individuen dar.

Eine solche genetische Variabilität stellt der von uns untersuchte T-786C-Polymorphismus dar, der innerhalb der Promotorregion des eNOS-Gens liegt. Hierbei kommt es zu einem singulären Nukleotidaustausch von Thymin gegen Cytosin, wodurch es zu einer starken Reduktion der Promotoraktivität und damit der Transkription kommt. Dies führt zu einer quantitativen Abnahme der entstehenden eNOS mit daraus resultierender Verminderung des gebildeten NO. Dieses wiederum nimmt aufgrund seiner vasodilatierenden, antithrombotischen, antiproliverativen, antiinflammatorischen, antioxidativen und antiatherogenen Eigenschaften eine zentrale Stellung in der Vermittlung der vaskulären Homöostase ein. Somit konnte der T-786C-Polymorphimsus bereits mit verschiedenen Erkrankungen des Gefäßsystems wie der Arteriosklerose, der koronaren Herzerkrankung und dem vermehrten Auftreten von Myokardinfarkten in Verbindung gebracht werden.

Über die Einflussnahme des Polymorphismus nach und während invasiver medizinischer Eingriffe wie einer herzchirurgischen Operation gibt es nur sehr wenige Ergebnisse, obwohl bereits nachgewiesen wurde, dass herzchirurgische Eingriffe mit einer extrakorporalen Zirkulation $\mathrm{zu}$ deutlichen Veränderungen der NO-Bioverfügbarkeit und -Synthese führen. Hintergrund $\mathrm{zu}$ dieser Arbeit war eine bereits 
nachgewiesene leichte Assoziation des Polymorphismus in Subgruppen herzchirurgischer Patienten, im Hinblick auf eine direkt peri-/postoperativ erhöhte Morbidität und Mortalität. Die Annahme war, dass es eine deutlichere Assoziation hinsichtlich der Morbidität und Mortalität im Langzeitverlauf geben könnte, da der Polymorphismus zu einer dauerhaften Verringerung der eNOS-Aktivität beiträgt.

Ziel der vorliegenden Arbeit war es, den klinischen Einfluss des T-786C-Polymorphismus auf die Mortalität und Morbidität im Langzeitverlauf von Patienten nach herzchirurgischen Eingriffen mit einer extrakorporalen Zirkulation zu untersuchen.

Das Patientenkollektiv unserer Studie umfasste 500 Patienten, welche mit Hilfe einer extrakorporalen Zirkulation in der Abteilung der Thorax-, Herz- und Gefäßchirurgie der Universitätsmedizin Göttingen eine Herzoperationen erhielten. Die Bestimmung des Polymorphismus wurde mittels PCR durchgeführt und die Patienten entsprechend ihres Genotyps in drei Gruppen unterteilt (TT-, TC- und CC-Allelträger). Um Daten hinsichtlich der Langzeitmorbidität und -Mortalität zu erhalten, erfolgte nach Ablauf von fünf Jahren die Datenerhebung mittels Fragebogen, direkten telefonischen Patientenkontakt und der Einholung der Auskunft über die Einwohnermeldeämter. Nach Abschluss aller Maßnahmen gelang es, eine Nachverfolgungsrate von $100 \%$ hinsichtlich des härtesten klinischen Parameters, der Langzeitmortalität, zu erreichen. Die Datenerhebung bezüglich der Langzeitmorbidität scheiterte jedoch an dem Informationsrücklauf auf diesem Gebiet. Somit konnten im Hinblick auf diese keine klinischen relevanten Daten erhoben werden, um aussagekräftige Ergebnisse zu treffen.

Bei einer 5-Jahres-Mortalität von 25\% ließen sich in den einzelnen Gruppen keine signifikanten Unterschiede hinsichtlich der Mortalität, bezogen auf die Genotypen, feststellen. Zwar zeigten homozygote C-Allelträger im Langzeitverlauf eine erniedrigte Überlebenszeit, jedoch ohne statistische Signifikanz. Somit ließ sich kein Genotyp als möglicher Risikofaktor für eine erhöhte Langzeitmortalität detektieren.

Demnach lässt sich zusammenfassend sagen, dass der T-786C-Polymorphismus keinen klinischen Einfluss sowohl auf die direkte peri-/postoperative Mortalität als auch 
auf die Langzeitmortalität von Patienten nach herzchirurgischen Eingriffen mit einer extrakorporalen Zirkulation hat. Somit kann er nicht als unabhängiger Risikofaktor zur Abschätzung individueller Überlebensraten verwendet werden und eignet sich daher auch nicht als Screeningparameter hinsichtlich der Langzeitmortalität herzchirurgischer Patienten.

Da die Folgen von kardiovaskulären Erkrankungen nicht nur ein medizinisches, sondern auch ein wirtschaftliches Problem darstellen, sollte die Herz-KreislaufForschung hinsichtlich weiterer Genassoziationsstudien intensiviert werden. Mit Hilfe solcher genetischen Marker, die mit einem gravierenden Verlauf assoziiert wären, bestünde die Möglichkeit, die Patienten in einem früheren Stadium zu identifizieren und dann rechtzeitig aggressiver und individualisierter $\mathrm{zu}$ behandeln. Dadurch könnten ebenfalls die Behandlungskosten solcher Patienten immens reduziert und eventuell neue Präventionsmaßnahmen sowie Therapieansätze entwickelt werden. 


\section{Literaturverzeichnis}

Abecasis GR, Altshuler D, Auton A, Brooks LD, Durbin RM, Gibbs RA, Hurles ME, McVean GA et al., 1000 Genomes Project Consortium (2010): A map of human genome variation from population-scale sequencing. Nature 467(7319): 1061-1073

Asimakopoulos G (1999): Mechanisms of the systemic inflammatory response. Perfusion 14(4): 269-277

Beckman JS, Koppenol WH (1996): Nitric oxide, superoxide, and peroxynitrite: the good, the bad, and ugly. Am J Physiol 271(5 Pt 1): C1424-1437

Beltrame JF, Sasayama S, Maseri A (1999): Racial heterogeneity in coronary vasomotor reactivity: differences between Japanese and Caucasian patients. J Am Coll Cardiol. 33(6): 1442-1452

Berk BC, Corson MA, Peterson TE, Tseng H (1995): Protein kinases as mediators of fluid shear stress stimulated signal transduction in endothelial cells: a hypothesis for calcium-dependent and calcium-independent events activated by flow. J Biomech 28(12): $1439-1450$

Bian K, Doursout MF, Murad F (2008): Vascular system: role of nitric oxide in cardiovascular diseases. J Clin Hypertens (Greenwich) 10(4): 304-310

Böger RH, Bode-Böger SM, Frölich JC (1996): The L-arginine-nitric oxide pathway: role in atherosclerosis and therapeutic implications. Atherosclerosis $\underline{127(1): 1-11}$

Borgdorff P, Fekkes D, Tangelder GJ (2002): Hypotension caused by extracorporeal circulation: serotonin from pump-activated platelets triggers nitric oxide release. Circulation 106(20): 2588-2593 
Brown GC (1999): Nitric oxide and mitochondrial respiration. Biochim Biophys Acta 1411(2-3): 351-369

Butler AR, Megson IL, Wright PG (1998): Diffusion of nitric oxide and scavenging by blood in the vasculature. Biochim Biophys Acta 1425(1): 168-176

Butler J, Rocker GM, Westaby S (1993): Inflammatory response to cardiopulmonary bypass. Ann Thorac Surg 55(2): 552-559

Cattaruzza M, Guzik TJ, Słodowski W, Pelvan A, Becker J, Halle M, Buchwald AB, Channon KM, Hecker M (2004): Shear stress insensitivity of endothelial nitric oxide synthase expression as a genetic risk factor for coronary heart disease. Circ Res $\underline{95}$ (8): $841-847$

Chatzizisis YS, Coskun AU, Jonas M, Edelman ER, Feldman CL, Stone PH (2007): Role of endothelial shear stress in the natural history of coronary atherosclerosis and vascular remodeling: molecular, cellular, and vascular behavior. J Am Coll Cardiol $\underline{49}$ (25): 2379-2393

Cheng C, van Haperen R, de Waard M, van Damme LC, Tempel D, Hanemaaijer L, van Cappellen GW, Bos J, Slager CJ, Duncker DJ et al (2005): Shear stress affects the intracellular distribution of eNOS: direct demonstration by a novel in vivo technique. Blood 106(12): 3691-3698

Colomba D, Duro G, Corrao S, Argano C, Di Chiara T, Nuzzo D, Pizzo F, Parrinello G, Scaglione R, Licata G (2008): Endothelial nitric oxide synthase gene polymorphisms and cardiovascular damage in hypertensive subjects: an Italian case-control study. Immun Ageing 5:4

Corson MA, James NL, Latta SE, Nerem RM, Berk BC, Harrison DG (1996): Phosphorylation of endothelial nitric oxide synthase in response to fluid shear stress. Circ Res 79(5): 984-991 
Crawford JH, Isbell TS, Huang Z, Shiva S, Chacko BK, Schechter AN, Darley-Usmar VM, Kerby JD, Lang JD Jr, Kraus D et al. (2006): Hypoxia, red blood cells, and nitrite regulate NO-dependent hypoxic vasodilation. Blood 107(2): 566-574

De Souza AC, Spyt TJ (1993): Release of vasoactive substances during cardiopulmonary bypass. Ann Thorac Surg 56 (2): 397-398

Dengel DR, Brown MD, Ferrell RE, Reynolds TH, Supiano MA (2007): A preliminary study on T-786C endothelial nitric oxide synthase gene and renal hemodynamic and blood pressure responses to dietary sodium. Physiol Res 56 (4): 393-401

Dosenko VE, Zagoriy VY, Lutay YM, Parkhomenko AN, Moibenko AA (2006): Allelic polymorphism in the promoter $(\mathrm{T} \rightarrow \mathrm{C})$, but not in exon $7(\mathrm{G} \rightarrow \mathrm{T})$ or the variable number tandem repeat in intron 4 , of the endothelial nitric oxide synthase gene is positively associated with acute coronary syndrome in the Ukrainian population. Exp Clin Cardiol 11(1): 11-13

Edmunds NJ, Moncada S, Marshall JM (2003): Does nitric oxide allow endothelial cells to sense hypoxia and mediate hypoxic vasodilatation? In vivo and in vitro studies. $\mathrm{J}$ Physiol 546(Pt 2): 521-527

Ferrari R, Ceconi C, Curello S, Cargnoni A, Pasini E, Visioli O (1991): The occurrence of oxidative stress during reperfusion in experimental animals and men. Cardiovasc Drugs Ther $\underline{5}$ (Suppl 2): 277-287

Fischer UM, Schindler R, Brixius K, Mehlhorn U, Bloch W (2007): Extracorporeal circulation activates endothelial nitric oxide synthase in erythrocytes. Ann Thorac Surg 84(6): 2000-2003

Förstermann U, Sessa WC (2012): Nitric oxide synthases: regulation and function. Eur Heart J 333(7): 829-837 
Förstermann U, Closs EI, Pollock JS, Nakane M, Schwarz P, Gath I, Kleinert H (1994): Nitric oxide synthase isozymes. Characterization, purification, molecular cloning, and functions. Hypertension $\underline{23}(6 \mathrm{Pt} 2): 1121-1131$

Furchgott RF, Zawadzki JV (1980): The obligatory role of endothelial cells in the relaxation of arterial smooth muscle by acetylcholine. Nature 288(5789): 373-376

Gaudino M, Andreotti F, Zamparelli R, Di Castelnuovo A, Nasso G, Burzotta F, Iacoviello L, Donati MB, Schiavello R, Maseri A et al. (2003): The -174G/C interleukin-6 polymorphism influences postoperative interleukin-6 levels and postoperative atrial fibrillation. Is atrial fibrillation an inflammatory complication? Circulation 108(Suppl 1): II195-199

Gewaltig MT, Kojda G (2002): Vasoprotection by nitric oxide: mechanisms and therapeutic potential. Cardiovasc Res 55(2): 250-260

Ghilardi G, Biondi ML, DeMonti M, Bernini M, Turri O, Massaro F, Guagnellini E, Scorza R (2002): Independent risk factor for moderate to severe internal carotid artery stenosis: T786C mutation of the endothelial nitric oxide synthase gene. Clin Chem 48(7): 989-993

Gomma AH, Elrayess MA, Knight CJ, Hawe E, Fox KM, Humphries SE (2002): The endothelial nitric oxide synthase (Glu298Asp and -786T $>$ C) gene polymorphisms are associated with coronary in-stent restenosis. Eur Heart J 23(24): 1955-1962

Govers R, Rabelink TJ (2001): Cellular regulation of endothelial nitric oxide synthase. Am J Physiol Renal Physiol 280(2): F193-206

Grocott HP, White WD, Morris RW, Podgoreanu MV, Mathew JP, Nielsen DM, Schwinn DA, Newman MF; Perioperative Genetics and Safety Outcomes Study (PEGASUS) Investigative Team (2005): Genetic polymorphisms and the risk of stroke after cardiac surgery. Stroke 36(9): 1854-1858 
Hardy GH (1908): Mendelian proportions in a mixed population. Science 28(706): 4950

Henker C: Einfluss des eNOS T-786C-Polymorphismus auf die Morbidität und Mortalität kardiochirurgischer Patienten. Med. Diss Göttingen 2011

Hingorani AD (2001): Polymorphisms in endothelial nitric oxide synthase and atherogenesis: John French Lecture 2000. Atherosclerosis 154(3): 521-527

Huang PL, Huang Z, Mashimo H, Bloch KD, Moskowitz MA, Bevan JA, Fishman MC (1995): Hypertension in mice lacking the gene for endothelial nitric oxide synthase. Nature 377(6546): 239-242

Hyndman ME, Parsons HG, Verma S, Bridge PJ, Edworthy S, Jones C, Lonn E, Charbonneau F, Anderson TJ (2002): The T-786 $\rightarrow$ C mutation in endothelial nitric oxide synthase is associated with hypertension. Hypertension 39(4): 919-922

Ignarro LJ, Buga GM, Wood KS, Byrns RE, Chaudhuri G (1987): Endothelium-derived relaxing factor produced and released from artery and vein is nitric oxide. Proc Natl Acad Sci U S A 84(24): 9265-9269

International Human Genome Sequencing Consortium (2004): Finishing the euchromatic sequence of the human genome. Nature 431(7011): 931-945

Joshi MS, Ferguson TB Jr, Han TH, Hyduke DR, Liao JC, Rassaf T, Bryan N, Feelisch M, Lancaster JR Jr (2002): Nitric oxide is consumed, rather than conserved, by reaction with oxyhemoglobin under physiological conditions. Proc Natl Acad Sci U S A 99(16): 10341-10346

Kelm M (1999): Nitric oxide metabolism and breakdown. Biochim Biophys Acta 1411(2-3): 273-289 
Ko NU, Rajendran P, Kim H, Rutkowski M, Pawlikowska L, Kwok PY, Higashida RT, Lawton MT, Smith WS, Zaroff JG et al. (2008): Endothelial nitric oxide synthase polymorphism (-786T- $>$ C) and increased risk of angiographic vasospasm after aneurysmal subarachnoid hemorrhage. Stroke 39(4): 1103-1108

Kröncke KD, Suschek CV, Kolb-Bachofen V (2000): Implications of inducible nitric oxide synthase expression and enzyme activity. Antioxid Redox Signal 2(3): 585-605

Kwon NS, Nathan CF, Gilker C, Griffith OW, Matthews DE, Stuehr DJ (1990): Lcitrulline production from L-arginine by macrophage nitric oxide synthase. The ureido oxygen derives from dioxygen. J Biol Chem 265(23): 13442-13445

Levin RL, Degrange MA, Bruno GF, Del Mazo CD, Taborda DJ, Griotti JJ, Boullon FJ (2004): Methylene blue reduces mortality and morbidity in vasoplegic patients after cardiac surgery. Ann Thorac Surg 77(2): 496-499

Levy S, Strausberg RL (2008): Human genetics: Individual genomes diversify. Nature 456(7218): 49-51

Liakopoulos OJ, Dörge H, Popov AF, Schmitto JD, Cattaruzza M, Schoendube FA (2006): Influence of eNOS gene polymorphisms $(894 \mathrm{G} / \mathrm{T} ;-786 \mathrm{C} / \mathrm{T})$ on postoperative hemodynamics after cardiac surgery. Thorac Cardiovasc Surg 54(4): 233-238

Lobato RL, White WD, Mathew JP, Newman MF, Smith PK, McCants CB, Alexander JH, Podgoreanu MV; Duke Perioperative Genetics and Safety Outcomes (PEGASUS) Investigative Team (2011): Thrombomodulin gene variants are associated with increased mortality after coronary artery bypass surgery in replicated analyses. Circulation 124(11 Suppl): S143-148

Marsden PA, Heng HH, Scherer SW, Stewart RJ, Hall AV, Shi XM, Tsui LC, Schappert KT (1993): Structure and chromosomal localization of the human constitutive endothelial nitric oxide synthase gene. J Biol Chem 268(23): 17478-17488 
Mathew JP, Podgoreanu MV, Grocott HP, White WD, Morris RW, Stafford-Smith M, Mackensen GB, Rinder CS, Blumenthal JA, Schwinn DA et al.; PEGASUS Investigative Team (2007): Genetic variants in P-selectin and C-reactive protein influence susceptibility to cognitive decline after cardiac surgery. J Am Coll Cardiol 49(19): 1934-1942

Menasché P, Haydar S, Peynet J, Du Buit C, Merval R, Bloch G, Piwnica A, Tedgui A (1994): A potential mechanism of vasodilation after warm heart surgery: The temperature-dependent release of cytokines. J Thorac Cardiovasc Surg 107(1): 293-299

Mezzetti A, Calafiore AM, Lapenna D, Deslauriers R, Tian G, Salerno TA, Verna AM, Bosco G, Pierdomenico SD, Caccurullo F (1995): Intermittent antegrade warm cardioplegia reduces oxidative stress and improves metabolism of the ischemicreperfused human myocardium. J Thorac Cardiovasc Surg 109(4): 787-795

Miller MJ, Sandoval M (1999): Nitric Oxide III. A molecular prelude to intestinal inflammation. Am J Physiol 276(4 Pt 1): G795-799

Miyamoto Y, Saito Y, Nakayama M, Shimasaki Y, Yoshimura T, Yoshimura M, Harada M, Kajiyama N, Kishimoto I, Kuwahara K et al. (2000): Replication protein A1 reduces transcription of the endothelial nitric oxide synthase gene containing a $786 \mathrm{~T} \rightarrow \mathrm{C}$ mutation associated with coronary spastic angina. Hum Mol Genet $\underline{9}(18)$ : 2629-2637

Moncada S, Palmer RM, Higgs EA (1988): The discovery of nitric oxide as the endogenous nitrovasodilator. Hypertension 12(4): 365-372

Mudra H, Büchele W, Mathias K, Schuler G, Sievert H, Theiss W (2006): [Interventional treatment of extracranial carotid stenoses: current status, requirements and indications]. Vasa $\underline{35}(2): 125-131$ 
Nakagawa T, Sato W, Glushakova O, Heinig M, Clarke T, Campbell-Thompson M, Yuzawa Y, Atkinson MA, Johnson RJ, Croker B (2007): Diabetic endothelial nitric oxide synthase knockout mice develop advanced diabetic nephropathy. J Am Soc Nephrol 18(2): 539-550

Nakayama M, Yasue H, Yoshimura M, Shimasaki Y, Kugiyama K, Ogawa H, Motoyama T, Saito Y, Ogawa Y, Miyamoto Y et al. (1999): T-786 $\rightarrow$ C mutation in the 5'-flanking region of the endothelial nitric oxide synthase gene is associated with coronary spasm. Circulation $\underline{99}(22): 2864-2870$

Nakayama M, Yasue H, Yoshimura M, Shimasaki Y, Ogawa H, Kugiyama K, Mizuno Y, Harada E, Nakamura S, Ito T et al. (2000): T(-786) $\rightarrow$ C mutation in the 5'-flanking region of the endothelial nitric oxide synthase gene is associated with myocardial infarction, especially without coronary organic stenosis. Am J Cardiol 86 (6): 628-634

Nashef SA, Roques F, Sharples LD, Nilsson J, Smith C, Goldstone AR, Lockowandt U (2012): EuroSCORE II. Eur J Cardiothorac Surg 41(4): 734-745

Palmer RM, Ferrige AG, Moncada S (1987): Nitric oxide release accounts for the biological activity of endothelium-derived relaxing factor. Nature 327(6122): 524-526

Philip I, Plantefeve G, Vuillaumier-Barrot S, Vicaut E, LeMarie C, Henrion D, Poirier O, Levy BI, Desmonts JM, Durand G et al. (1999): G894T polymorphism in the endothelial nitric oxide synthase gene is associated with an enhanced vascular responsiveness to phenylephrine. Circulation 99(24): 3096-3098

Podgoreanu MV, White WD, Morris RW, Mathew JP, Stafford-Smith M, Welsby IJ, Grocott HP, Milano CA, Newman MF, Schwinn DA; Perioperative Genetics and Safety Outcomes Study (PEGASUS) Investigative Team (2006): Inflammatory gene polymorphisms and risk of postoperative myocardial infarction after cardiac surgery. Circulation 114(1 Suppl): I275-281 
Popov AF, Hinz J, Schulz EG, Schmitto JD, Wiese CH, Quintel M, Seipelt R, Schoendube FA (2009): The eNOS 786C/T polymorphism in cardiac surgical patients with cardiopulmonary bypass is associated with renal dysfunction. Eur J Cardiothorac Surg $\underline{36}(4): 651-656$

Popov AF, Henker C, Schmitto JD, Wiese CH, Coskun KO, Moerer O, Danner BC, Schoendube FA, Quintel M, Hinz J (2010): Clinical relevance of eNOS T-786C polymorphism for hospital mortality and morbidity in cardiac surgical patients. $\mathrm{J}$ Cardiovasc Surg (Torino) 51(2): 265-272

Quyyumi AA, Dakak N, Andrews NP, Husain S, Arora S, Gilligan DM, Panza JA, Cannon RO 3rd (1995): Nitric oxide activity in the human coronary circulation. Impact of risk factors for coronary atherosclerosis. J Clin Invest 95(4): 1747-1755

Rossi GP, Cesari M, Zanchetta M, Colonna S, Maiolino G, Pedon L, Cavallin M, Maiolino P, Pessina AC (2003): The T-786C endothelial nitric oxide synthase genotype is a novel risk factor for coronary artery disease in Caucasian patients of the GENICA study. J Am Coll Cardiol 41(6): 930-937

Ruel M, Bianchi C, Khan TA, Xu S, Liddicoat JR, Voisine P, Araujo E, Lyon H, Kohane IS, Libermann TA et al. (2003): Gene expression profile after cardiopulmonary bypass and cardioplegic arrest. J Thorac Cardiovasc Surg 126(5): 1521-1530

Ruel M, Khan TA, Voisine P, Bianchi C, Sellke FW (2004): Vasomotor dysfunction after cardiac surgery. Eur J Cardiothorac Surg 26(5): 1002-1014

Ruvolo G, Greco E, Speziale G, Tritapepe L, Marino B, Mollace V, Nisticò G (1994): Nitric oxide formation during cardiopulmonary bypass. Ann Thorac Surg 57(4): 10551057

Schmidt HH, Walter U (1994): NO at work. Cell $\underline{78(6): ~ 919-925 ~}$ 
Seddon M, Shah AM, Casadei B (2007): Cardiomyocytes as effectors of nitric oxide signalling. Cardiovasc Res 75(2): 315-326

Sellke FW (1999): Vascular changes after cardiopulmonary bypass and ischemic cardiac arrest: roles of nitric oxide synthase and cyclooxygenase. Braz J Med Biol Res 32(11): 1345-1352.

Sergeant P, Meyns B, Wouters P, Demeyere R, Lauwers P (2003): Long-term outcome after coronary artery bypass grafting in cardiogenic shock or cardiopulmonary resuscitation. J Thorac Cardiovasc Surg 126(5): 1279-1286

Shahian DM, O'Brien SM, Sheng S, Grover FL, Mayer JE, Jacobs JP, Weiss JM, Delong ER, Peterson ED, Weintraub WS et al. (2012): Predictors of long-term survival after coronary artery bypass grafting surgery: results from the Society of Thoracic Surgeons Adult Cardiac Surgery Database (the ASCERT study). Circulation 125(12): $1491-1500$

Snyder SH (2009): Obituary: Robert Furchgott (1916-2009). Nature 460(7251): 47

Squadrito GL, Pryor WA (1998): Oxidative chemistry of nitric oxide: the roles of superoxide, peroxynitrite, and carbon dioxide. Free Radic Biol Med 25(4-5): 392-403

Stafford-Smith M, Podgoreanu M, Swaminathan M, Phillips-Bute B, Mathew JP, Hauser EH, Winn MP, Milano C, Nielsen DM, Smith M et al.; Perioperative Genetics and Safety Outcomes Study (PEGASUS) Investigative Team (2005): Association of genetic polymorphisms with risk of renal injury after coronary bypass graft surgery. Am J Kidney Dis $\underline{45}(3): 519-530$

Statistisches Bundesamt (2010): Krankheitskosten 2002, 2004, 2006 und 2008. Fachserie 12 Reihe 7.2, Artikelnummer: 2120720089004, Statistisches Bundesamt, Wiesbaden 2010 
Statistisches Bundesamt (2012): Todesursachen in Deutschland 2011. Fachserie 12 Reihe 4, Artikelnummer: 2120400117004, Statistisches Bundesamt, Wiesbaden 2012

Stumpe T, Decking UK, Schrader J (2001): Nitric oxide reduces energy supply by direct action on the respiratory chain in isolated cardiomyocytes. Am J Physiol Heart Circ Physiol 280(5): H2350-2356

Tomasdottir H, Hjartarson H, Ricksten A, Wasslavik C, Bengtsson A, Ricksten SE (2003): Tumor necrosis factor gene polymorphism is associated with enhanced systemic inflammatory response and increased cardiopulmonary morbidity after cardiac surgery. Anesth Analg 97(4): 944-949

Tossios P, Bloch W, Huebner A, Raji MR, Dodos F; Klass O, Suedkamp M, Kasper SM, Hellmich M, Mehlhorn U (2003): N-acetylcysteine prevents reactive oxygen species-mediated myocardial stress in patients undergoing cardiac surgery: results of a randomized, double-blind, placebo-controlled clinical trial. J Thorac Cardiovasc Surg 126(5): $1513-1520$

Traub O, Berk BC (1998): Laminar shear stress: mechanisms by which endothelial cells transduce an atheroprotective force. Arterioscler Thromb Vasc Biol 18(5): 677-685

Uematsu M, Ohara Y, Navas JP, Nishida K, Murphy TJ, Alexander RW, Nerem RM, Harrison DG (1995): Regulation of endothelial cell nitric oxide synthase mRNA expression by shear stress. Am J Physiol 269(6 Pt 1): C1371-1378

van Beynum IM, Mooij C, Kapusta L, Heil S, den Heijer M, Blom HJ (2008): Common $894 \mathrm{G}>\mathrm{T}$ single nucleotide polymorphism in the gene coding for endothelial nitric oxide synthase (eNOS) and risk of congenital heart defects. Clin Chem Lab Med $\underline{46}(10)$ : $1369-1375$ 
Waldman SA, Murad F (1988): Biochemical mechanisms underlying vascular smooth muscle relaxation: the guanylate cyclase-cyclic GMP system. J Cardiovasc Pharmacol 12(Suppl 5): S115-S118

Wang XL, Wang J (2000): Endothelial nitric oxide synthase gene sequence variations and vascular disease. Mol Genet Metab $\underline{70}$ (4): 241-251

Welsby IJ, Podgoreanu MV, Phillips-Bute B, Mathew JP, Smith PK, Newman MF, Schwinn DA, Stafford-Smith M; Perioperative Genetics and Safety Outcomes Study (PEGASUS) Investigative Team (2005): Genetic factors contribute to bleeding after cardiac surgery. J Thromb Haemost $\underline{3}$ (6): 1206-1212

Wink DA, Mitchell JB (1998): Chemical biology of nitric oxide: Insights into regulatory, cytotoxic, and cytoprotective mechanisms of nitric oxide. Free Radic Biol Med 25(4-5): 434-456

Wood J, Garthwaite J (1994): Models of the diffusional spread of nitric oxide: implications for neural nitric oxide signalling and its pharmacological properties. Neuropharmacology 33 $\underline{3}(11): 1235-1244$

Wu C, Camacho FT, Wechsler AS, Lahey S, Culliford AT, Jordan D, Gold JP, Higgins RS, Smith CR, Hannan EL (2012): Risk score for predicting long-term mortality after coronary artery bypass graft surgery. Circulation 125(20): 2423-2430

Zanchi A, Moczulski DK, Hanna LS, Wantman M, Warram JH, Krolewski AS (2000): Risk of advanced diabetic nephropathy in type 1 diabetes is associated with endothelial nitric oxide synthase gene polymorphism. Kidney Int 57(2): 405-413

Zeng Z, Li L, Zhang Z, Li Y, Wei Z, Huang K, He L, Shi Y (2010): A meta-analysis of three polymorphisms in the endothelial nitric oxide synthase gene (NOS3) and their effect on the risk of diabetic nephropathy. Hum Genet 127(4): 373-381 
Ziegeler S, Tsusaki BE, Collard CD (2003): Influence of genotype on perioperative risk and outcome. Anesthesiology 99(1): 212-219 


\section{Abbildungsverzeichnis}

Abbildung 1: Anschreiben an die Hausärzte

Abbildung 2: Fragebogen Seite 1

Abbildung 3: Fragebogen Seite 2

Abbildung 4: Detaillierte Übersicht der Nachverfolgungszeit des Gesamtkollektivs 34

Abbildung 5: Detaillierte Übersicht der Nachverfolgungszeit des TT-Genotyp 34

Abbildung 6: Detaillierte Übersicht der Nachverfolgungszeit des TC-Genotyp 35

Abbildung 7: Detaillierte Übersicht der Nachverfolgungszeit des CC-Genotyp 35

Abbildung 8: Langzeitüberlebensraten der Patienten anhand ihres Genotyps $($ Log-rank-Test $\mathrm{p}=0,09)$ 


\section{Tabellenverzeichnis}

Tabelle 1: Genotypen- und Allelverteilung 36

Tabelle 2: Alters- und Geschlechtsverteilung 37

Tabelle 3: Operationszeitpunkt und Art der Eingriffe 38

Tabelle 4: Todesursachen 40

Tabelle 5: Peri-/postoperative Mortalität mit Subgruppen-Analyse 41

Tabelle 6: 5-Jahres-Mortalität mit Subgruppen-Analyse 42

Tabelle 7: Mortalitätsraten im Vergleich 43

Tabelle 8: Überlebensdauer, Alter bei Studien-Einschluss und Tod 43 


\section{Danksagung}

An dieser Stelle möchte ich mich bei Herrn Prof. Dr. med. M. Quintel (Direktor der Klinik für Anästhesiologie im Zentrum Anaesthesiologie-, Rettungs- und Intensivmedizin, Universitätsmedizin Göttingen) für die Überlassung des interessanten Themas sowie für die Beratung und die großzügige Bereitstellung von Laborräumen und Geräten bedanken.

Ebenfalls möchte ich mich bei Herrn Prof. Dr. med. Dipl.-Phys. F.A. Schöndube (Direktor der Klinik für Thorax-, Herz- und Gefäßchirurgie im Zentrum Chirurgie, Universitätsmedizin Göttingen) für die Überlassung der bereits vorhandenen Daten sowie die Möglichkeit der erneuten Datenerhebung bedanken.

Meinem wissenschaftlichen Betreuer, Prof. Dr. med. J. Hinz (Klinik für Anästhesiologie im Zentrum Anaesthesiologie-, Rettungs- und Intensivmedizin, Universitätsmedizin Göttingen) gilt der besondere Dank für sein großes Interesse und die vielen praktischen Hinweise im Rahmen der Experimente und des Schreibens der Arbeit sowie für die intensive Betreuung in jeder Phase des Entstehens dieser Arbeit.

Auch möchte ich mich bei meinem zweiten Betreuer PD Dr. med. A. Popov (Klinik für Thorax-, Herz- und Gefäßchirurgie im Zentrum Chirurgie, Universitätsmedizin Göttingen) bedanken, der mir ebenfalls sehr behilflich war und immer wieder mit anregenden Diskussionen und hilfreichen Ratschlägen zur Seite stand.

Mein zusätzlicher Dank gilt unbekannterweise den Hausärzten sowie den Beamten der Einwohnermeldeämter, die die Datenerhebung der Studie und somit die Fertigstellung dieser Arbeit erst möglich machten. 


\section{Lebenslauf}

Am 21.05.1977 wurde ich als erstes und einziges Kind der Krankenschwester Janina Bireta und des Diplomvolkswirtes Stanislaw Bireta in Jawor (Polen) geboren. Dort besuchte ich die Janusz Korczak Volksschule, bis wir 1986 in die Bundesrepublik Deutschland übersiedelten. Anschließend besuchte ich bis 1988 die Grundschule Godehard sowie von 1988 bis 1990 die Orientierungsstufe Bonifatiusschule II in Göttingen. Nach Abschluss der Orientierungsstufe wechselte ich auf die Realschule Bonifatius II, die ich 1994 mit einem Erweitertem Sekundarabschluss I beendete. Nachfolgend besuchte ich das Hainberg-Gymnasium und beendete dort meine schulische Laufbahn mit dem Abitur im Jahr 1997. Anschließend folgte ein Freiwilliges Soziales Jahr im Krankenhaus Neu Bethlehem in der Abteilung Chirurgie.

Zum Sommersemester 2000 nahm ich das Studium der Humanmedizin an der Georg-August-Universität in Göttingen auf. Während meines Studiums famulierte ich innerhalb verschiedenster Bereiche der Medizin in Göttingen und Osnabrück. Nach vier regulären vorklinischen Semestern legte ich im Frühjahr 2002 erfolgreich die Ärztliche Vorprüfung ab. Es folgte im Frühjahr 2003 der Abschluss des 1. Teils der Ärztlichen Prüfung. Im Sommer 2005 legte ich den 2. Teil der Ärztlichen Prüfung ab und begann im Herbst 2005 das praktische Jahr in der Universitätsmedizin Göttingen. Mein Humanmedizinstudium beendete ich im Herbst 2006 mit dem 3. Staatsexamen.

Am 01.01.2007 begann ich meine Tätigkeit als Arzt in der Klinik für Thorax-, Herz- und Gefäßchirurgie im Zentrum Chirurgie der Universitätsmedizin Göttingen und bin seitdem dort beschäftigt. Arbeitsbegleitend begann ich im Juni 2010 meine Dissertationsarbeit unter der Leitung von Herrn Prof. Dr. med. J. Hinz in der Klinik für Anästhesiologie im Zentrum Anaesthesiologie-, Rettungs- und Intensivmedizin der Universitätsmedizin Göttingen. 